\title{
APROXIMACIÓN A UN ANÁLISIS NORMATIVO DE LA REVISIÓN JUDICIAL*
}

\section{FEDERICO SZCZARANSKI VARGAS**}

RESUMEN: El presente trabajo busca llevar adelante un estudio de cómo el análisis normativo podría aplicarse a la revisión judicial de constitucionalidad relativa a las cláusulas de derechos fundamentales. Ello supone analizar si esas cláusulas son susceptibles de ser entendidas como normas constitucionales que pueden ser incompatibles con normas legales o infringidas por la acción del legislador. Finalmente -y luego de discutir los defectos de la "fórmula del peso" y de la teoría de la "lectura moral" de Dworkin-, se analizarán someramente las implicancias del modelo propuesto tanto en la teoría del razonamiento jurídico, como en la concepción de los derechos fundamentales.

PALABRAS CLAVE: Inconstitucionalidad - normas permisivas - derechos fundamentales.

\section{APPROACH TO A NORMATIVE ANALYSIS OF JUDICIAL REVIEW}

ABSTRACT: This paper aims to study how a normative analysis could be applied to the judicial review of constitutionality concerning fundamental rights clauses. This involves analyzing whether such clauses are susceptible to be understood as constitutional norms that can be inconsistent with law or violated by legislative action. Finally -and after discussing the disadvantages of the "weight formula" and Dworkin's "moral reading" theory-, we briefly discuss the implications of the proposed

\footnotetext{
Varios de los temas tratados en este trabajo fueron conversados con los profesores Fernando Guanarteme Sánchez Lázaro, Esteban Szmulewicz y Juan José Rondón, a quienes agradezco la gentileza de haber revisado y comentado versiones preliminares del presente artículo. Agradezco también a Andrés Chamorro y Catalina Espinoza.

Fecha de recepción: 5 de agosto de 2013.

Fecha de aceptación: 13 de noviembre de 2013,

** Licenciado en Ciencias Jurídicas y Sociales, Universidad de Chile; Magíster en Derecho Penal, Universidad de Talca y Universidad Pompeu Fabra. Centro de Estudios Penales y Penitenciarios, Facultad de Derecho, Universidad Mayor. Correo electrónico: federico.szczaranski@umayor.cl.
} 
model in both the theory of legal reasoning and in the conception of fundamental rights.

KEY WORDS: Unconstitutionality - permissive norms - fundamental
rights.

\section{INTRODUCCIÓN}

El camino adoptado por el positivismo jurídico ha olvidado las ideas que lo inspiraron en su origen ${ }^{1}$. En su ataque al common law, Bentham buscaba evitar que el Derecho dependiera en última instancia de su conformidad con una razón artificial que solo abogados dominan, y que supedita a la legislación a la correcta comprensión del derecho preexistente: el common law, como derecho superior, no había sido hecho por nadie, y sus palabras, que no pueden ser encontradas en ningún libro, solo son pronunciadas por los jueces ${ }^{2}$. Sobre el resultado del sometimiento a ese derecho invisible, Bentham señala: while the rights we are bid to be grateful for are mere illusions, the punishments we are made to undergo are sad realities (...) we have never heard of any tyrant in such sort cruel, as to punish men for disobedience to laws or orders which he had keep them from the knowledge of ${ }^{3}$. De esta forma, el positivismo, al afirmar la contingencia del derecho y negar que este exista de manera preestablecida a las decisiones políticas, como un desenvolvimiento de la razón natural, podía ser visto como una teoría emancipadora que servía para reducir la posibilidad de arbitrariedad de los jueces. Para ese fin, se ataca la idea de razonabilidad como un concepto que pueda servir para identificar el derecho ${ }^{4}$.

El problema, explica Atria en "La ironía del positivismo jurídico", se presenta por el olvido del positivismo de esa finalidad, lo que se manifestaría de manera concluyente en la tesis de las fuentes de Raz. Conforme a ella, una razón es jurídica solo en la medida que su existencia y contenido pueda establecerse únicamente en consideración a hechos sociales, sin recurrir a argumentos morales ${ }^{5}$, ya que ello posibilita distinguir entre dos momentos: uno deliberativo, en que se evalúa el mérito de los cursos de acción posibles; y otro ejecutivo, en que no se hace tal evaluación, sino que se recuerda aquel curso que fue decidido, y se afirma si una acción

Atria, Fernando (2004b) "La ironía del positivismo jurídico". DOXA, n 27, pp. 81 a 139.

Bentham, Jeremy (1829) "Petition for Codification". En: BENTHAM, Jeremy, Justice and codification, London: Robert Heward, p. 2.

BeNTHAM (1829) p. 4

Atria (2004b) p. 108 y ss.

Raz, Joseph (1986) El concepto de sistema jurídico. Traducción de Rolando Tamayo y Salmorán. México: Universidad Autónoma de México, p. 255. 
dada es coincidente o no con esa decisión. En ese modelo, solo hay derecho cuando las instituciones judiciales reconocen la diferencia de momentos; es decir, cuando la identificación de la decisión no depende de argumentos morales y solo atienden a la validez autoritativamente establecida de la decisión adoptada ${ }^{6}$. A consecuencia de ello, los casos en los que la legislación hace referencia a conceptos cargados moralmente, la opción del positivismo duro ${ }^{7}$ es negar que esa disposición sea jurídicamente vinculante, por cuanto la identificación de su contenido supone una evaluación moral. De esta forma, por ejemplo, al referirse a una prohibición de aplicar castigos crueles, Raz sostiene que el Derecho otorga discreción al juez para prohibir lo que él considere que es $\mathrm{cruel}^{8}$. El resultado es justamente el que Bentham quería evitar: al no haber derecho, el juez tiene discreción y puede fallar como le parezca moralmente aceptable, ya que solo con el fallo del juez se llega al momento ejecutivo9.

El problema es aún mayor respecto de los casos constitucionales: para el positivismo, dados los términos abstractos y moralmente cargados de la Constitución, el juez constitucional goza de una libertad absoluta para resolver, efectuando el juicio de constitucionalidad sin límites jurídicos de ningún tipo. Con ello, argumenta Atria, el positivismo regala la batalla al neoconstitucionalismo, y no cuenta con un modo de hacer frente a la "lectura moral de la Constitución" que propone Dworkin, o al juicio de proporcionalidad/ponderación de Alexy; ambos caracterizados por otorgar amplios márgenes de discreción al juez, por cuanto descansan prioritariamente en lo que Wroblewski denominaba "contexto funcional" de interpretación ${ }^{10}$, en el cual la evaluación de los factores a considerar depende fuertemente de las convicciones morales del adjudicador ${ }^{11}$.

RAz (1986) pp. 255 y ss.

Atria (2004b) p. 86.

RAz, Joseph (1985b) "Authority, law and Morality". The Monist, Vol. 68, Issue n 3, p. 317: "Since, by this rule of interpretation, no more specific intention is attributable to the law-maker, the law gives discretion to the courts to forbid punishments they consider cruel (this reflects the lack of specificity in the law) and instructs them to forbid those which are cruel".

9 Raz (1986) p. 258.

10 Wroblewski, Jerzy (1985) Constitución y teoría de la interpretación jurídica. Traducción de Arantxa Azurza, Madrid: Civitas, p. 56. Al respecto, Nogueira indica que las reglas constitucionales se van transformando con el tiempo y con los acontecimientos sociales, los cuales "van haciendo variar el sentido y alcance de los vocablos empleados" (Nogueira, Humberto (2012) "La concepción de Constitución, el bloque de constitucionalidad de derecho fundamentales y el control de convencionalidad en la práctica jurisprudencial del tribunal Constitucional y la Corte suprema de Justicia de Chile". En: Pfeffer, Emilio (Coord.) Derechos Fundamentales. Libro homenaje a Francisco Cumplido Cereceda, Santiago: Editorial Jurídica de Chile, p. 222.).

11 Sant'ana, Adriano (2012) "Mutación constitucional y concreción normativa: cómo la estructura de la norma se relaciona con los cambios informales de la Constitución”. Estudios Constitucionales, año $10, \mathrm{n}^{\circ} 2$, p. 386, hace referencia a "la evolución y complejidad de las relaciones humanas". 
En este esquema, el estudio que a continuación se expone, busca ofrecer un modelo de resolución de los casos de revisión judicial de constitucionalidad relativos a cláusulas de derechos fundamentales que, utilizando de base una teoría de las normas, contribuya al programa original y abandonado del positivismo jurídico, que enaltecía el valor del derecho legislado, logrando reducir la discrecionalidad del juez constitucional, sin que ello signifique un compromiso con una concepción "mecanicista" de la adjudicación.

\section{1) IDENTIFICACIÓN DE LAS NORMAS}

Una consecuencia de la aproximación al juicio de constitucionalidad desde la teoría de las normas consiste en que se debe distinguir la redacción de cada derecho fundamental en particular, por cuanto de ella dependerá si acaso el enunciado contiene elementos suficientes como para afirmar la existencia de una norma. De ello se sigue que hay una diferencia relevante entre cláusulas de derechos fundamentales redactadas en términos amplios y abstractos, y aquellas en las que el constituyente ha precisado acciones específicas, al menos implícitamente; lo que -como veremos- tiene lugar en caso que la misma Constitución establezcan suficientes relaciones entre los conceptos utilizados.

El punto de partida para este análisis consiste en determinar la relación existente entre la creación de leyes y reglamentos, por un lado, y la incorporación de normas en un sistema jurídico, por otro. Así, al promulgar una ley, la autoridad crea una disposición jurídica, es decir, material jurídico autoritativo ${ }^{12}$, cuyo significado puede ser entendido como una norma si es que a su respecto se cumplen ciertos requisitos.

El tipo de enunciado jurídico con el que esta operación parece realizarse más fácilmente, corresponde a los tipos penales de la parte especial, los cuales pueden verse sin mayor problema como material jurídico a partir del cual es posible extraer normas de conducta ${ }^{13}$ dirigidas a los ciudadanos ${ }^{14}$, poseedoras tanto de una faz retrospectiva que sirve de bare-

Al respecto: Raz (1986) pp. 180 y ss.

Norma secundaria en Kelsen (Kelsen, Hans (2008) Teoría pura del derecho. Traducción de Moisés Nilve. $4^{\circ}$ Ed., Buenos Aires: Eudeba, p. 61).

14 Hruschka, Joachim (1994) “Reglas de comportamiento y reglas de imputación”. Anuario de Derecho Penal, Fascículo III, septiembre-diciembre, pp. 344 y ss. Igualmente: KInDHÄUser, Urs (2009) "La lógica de la construcción del delito". Traducción de Juan Pablo Mañalich. Revista de Análisis Especializado de jurisprudencia, n 14, p. 500, también en KindhäUser, Urs (2005) “¿Indiferencia cómo dolo?”. Traducción de Percy García. En: KinDhäUser, Urs; García, Percy; Pastor, Nuria, Cuestiones actuales de derecho penal general y patrimonial. Lima: Universidad de Piura, p. 41; de la misma manera en: KindHëUser, Urs (2010) “¿Qué es la imprudencia?”, pp. 3 y ss. En: IV Seminario Internacional de Derecho 
mo para juzgar si se ha cumplido o no con un estándar; como de una faz prospectiva que indica cómo los ciudadanos se deben comportar, proscribiendo de esa manera la realización de los tipos mediante prohibiciones de realización y órdenes de evitación, de forma tal que ellas determinan un estatus deóntico ${ }^{15}$ de ciertos comportamientos, constituyéndose así en el fundamento de obligaciones ${ }^{16}$.

Estas normas, a su vez, se extraen desde los tipos penales mediante la formulación contradictoria del supuesto de hecho de la norma de sanción ${ }^{17}$, la cual se dirige al juez habilitándolo para que aplique una pena en caso de configurarse el hecho descrito en el tipo ${ }^{18}$.

Penal (16.09.2010), Disponible en: http://www.scribd.com/doc/38024280/Artculo-Profkindhuser-Que-Es-La-Imprudencia [fecha de consulta: 14 de enero de 2013]. En Chile, véase: Mañalich, Juan Pablo (2005a) "Condiciones generales de la punibilidad". Revista de Derecho de la Universidad Adolfo Ibáñez, n², p. 388. Desde una teoría del delito como infracción: Mir, Santiago (2011) Derecho Penal. Parte General. 9a ed., Barcelona: Reppetor, pp. 61 y 62.; Silva, Jesús (2010) Aproximación al derecho penal contemporáneo. 2a ed., Montevideo-Buenos Aires: B de f, p. 506. En los casos de Silva y Mir, las normas de conducta se configuran considerando conjuntamente los tipos de la parte especial con los enunciados de las causas de justificación, así, las normas de conducta propia del delito de homicidio no prohíbe absolutamente matar a otro, sino que matar a otro en aquellos casos en los que esa conducta no se encuentra permitida (Silva (2010) pp. 532 y ss.; Mir, Santiago (2003) Introducción a las bases del derecho penal. $2^{\text {a }}$ ed., Montevideo-Buenos Aires: B de f, pp. 31 y 32.). En cambio, en la teoría de Mañalich, los enunciados de la parte especial no se funden con las causas de justificación para dar lugar a una única norma de comportamiento, sino que sirven para configurar normas apartes, conforme a las cuales la conducta que vulnera la norma prohibitiva o de mandato, pero que se encuentra permitida en función de la norma permisiva extraída de la causa de justificación, no es simplemente una conducta indiferente para el derecho penal (como lo serían las conductas derechamente atípicas), sino que constituye un comportamiento respecto del cual el derecho impone deberes de tolerancia (MAŃALICH (2005a) p. 422). En cualquier caso, la principal diferencia entre ambas teorías se encuentra en la necesidad de constatar aspectos subjetivos en el destinatario de la norma para poder afirmar que este la ha infringido: Mir y Silva, destacando que la norma corresponde a un imperativo dirigido a la voluntad del destinatario, afirman que ella solo puede ser infringida voluntariamente, razón por la cual el dolo y el conocimiento de la norma constituyen condiciones de aplicabilidad de la misma (Mrr (2011) p. 71). En contra de ello, Mañalich afirma que "la pregunta de si una persona es capaz física y psíquicamente de comportarse de modo adecuado a la norma no es una pregunta que concierna a la antinormatividad", ya que ese juicio es puramente deductivo, correspondiendo a una operación de subsunción (Mañalich, Juan Pablo (2010) "Norma e imputación como categoría del hecho punible". $R E J, \mathrm{n}^{\circ} 12$, pp. 175 y 176); por lo que será al momento de efectuar el juicio de imputación en el que se analizará si la infracción a la norma de conducta puede ser atribuida a ciertas capacidades del sujeto (Mañalich (2005a) p. 389; igualmente KindhäUser (2009) pp. 504 y ss.). Un paralelo entre teorías de infracción e imputación: Silva, Jesús (2003) Normas y acciones en el derecho penal. Buenos Aires: Hammurabi, pp. 33 y ss.

15 Von Wright, Georg Henrik (1970) Norma y acción. Una investigación lógica. Traducción de Pedro García. Madrid: Tecnos, p. 116.

Mañalich (2010) p. 171.

O norma primaria en Kelsen (Kelsen (2008) p. 61).

MañAlich (2010) p. 172. Como veremos más adelante, y a fin de compatibilizar la teoría de las normas con la teoría de la adjudicación, acá se sostiene que para la formulación de la norma de conducta, no se considera la totalidad del supuesto de hecho de la norma de sanción. 
De esta forma, tomando un tipo penal que estableciera que "el que mate a otro será castigado" tenemos que dicho tipo, entendido como norma de comportamiento, se deja formular de la siguiente manera: "prohibido matar".

Siguiendo a Von Wright, y en lo que a nuestro análisis interesa, podemos indicar como elementos de la norma ${ }^{19}$ el que ella tiene carácter de "deber", en particular prohibitivo, correspondiendo entonces a una norma de obligación; su destinatario es cualquier hombre; y su contenido, esto es, aquello que no debe hacerse, es matar, lo que corresponde a una acción ${ }^{20}$. Respecto de este último elemento, Von Wright lo vincula a la noción de "suceso", el cual supone un cambio en el mundo que es intrínseco lógicamente a la acción, y que en este caso, correspondería a una transición de un estado de cosas a otro ${ }^{21}$.

Ya definida, la norma puede entenderse como razón para la acción, o en este caso, para la abstención de la acción "matar". Si una razón operativa de primer orden es aquella que, simplemente, en caso de ser aceptada fundamenta una actitud crítica de desaliento hacia las creencias en conflicto y de aliento a las correspondientes ${ }^{22}$; la norma jurídica no solo tiene la pretensión de fundamentar esa actitud de desaliento a lo que contradice la abstención de "matar", sino que además busca constituirse en una razón para -respecto de la acción de matar- no considerar ninguna otra razón como relevante para la acción. En esa medida, la norma es una razón de primer orden para no realizar el acto normativo, y una razón excluyente de segundo orden para no actuar por otras razones en conflicto ${ }^{23}$.

\section{2) LA INCONSTITUCIONALIDAD DESDE LA TEORÍA DE LAS NORMAS}

En este esquema, el análisis de la constitucionalidad de un precepto de este tipo consta de dos aristas: por un lado, la inconstitucionalidad puede afirmarse por un defecto en la dictación de la disposición jurídica que es entendida como norma legal; y por otro, puede haber un conflicto directamente entre la norma legal y otra norma incompatible con ella de jerarquía constitucional: son inconstitucionalidades de procedimiento o de contenido ${ }^{24}$ respectivamente.

En el primer caso, típicamente nos encontraremos con que la inconstitucionalidad de la norma se explicará por cuanto en el establecimiento

\footnotetext{
19 Al respecto, puede verse también RAZ, Joseph (1991) Razón práctica y normas. Traducción de Juan Ruiz. 2a ed., Madrid: Centro de Estudios Constitucionales, p. 56.

20 Von Wright, (1970) pp. 87 y ss.

21 VON WRIGHT (1970) p. 56.

22 Raz (1991) pp. 36 y ss.

23 Raz (1991) p. 66.

24 En un sentido hasta cierto punto similar, véase: Kelsen, Hans (1995) ¿Quién debe ser el defensor de la Constitución? Traducción de Roberto Brie. 2a ed., Madrid: Tecnos, pp. 24 y 25.
} 
de la disposición jurídica cuestionada no se ha ejercido correctamente el poder normativo que la ha generado ${ }^{25}$, como ocurriría respecto de las disposiciones operativas ${ }^{26}$ constitucionales de competencia o procedimiento; y ello, a su vez -en lenguaje hartiano-, se juzgará en base al seguimiento de la regla de cambio ${ }^{27}$. Así, la norma dejará de formar parte de nuestro ordenamiento con independencia de si ella se encuentra o no en conflicto con otra norma.

En el segundo caso, en cambio, se intenta afirmar la contradicción de la Constitución no en la infracción de una regla relativa a la disposición normativa, sino que por cuanto se entiende -por parte de quien alega la inconstitucionalidad- que la norma misma es contraria a una norma constitucional (este supuesto, en todo caso, sería compatible con un defecto de la disposición jurídica fundado en que el poder normativo que se ha delegado al legislador se encontraría limitado por una prohibición ${ }^{28} \mathrm{de}$ crear disposiciones jurídicas que configuren normas contrarias a la Constitución).

Llevando lo anterior al caso particular de inconstitucionalidad por contradicción a los derechos fundamentales, es posible distinguir si se pretende que la cláusula de derecho fundamental constituya una norma constitucional incompatible con la norma legal o si la cláusula de derecho fundamental pretende constituir una norma que debe respetarse por el legislador para la correcta dictación de una disposición jurídica.

\section{1) INCONSTITUCIONALIDAD POR CONTENIDO: CONTRADICCIÓN ENTRE NORMA LEGAL Y NORMA CONSTITUCIONAL DERECHO FUNDAMENTAL}

En este caso, se sostiene que la norma legal misma contradice una norma de derecho fundamental. Para ello, veamos qué es lo que estaría haciendo en ese supuesto un Tribunal al declarar la inconstitucionalidad de una disposición legal por contradecir de esa manera derechos fundamentales:

En este caso, la declaración de inconstitucionalidad de un precepto legal corresponde -normativamente entendida- a la negación de la norma subyacente a ese precepto, y en esa medida -entendiendo que la norma

25 Von Wright (1970) pp. 195 y ss. Respecto de la relación entre reglas de competencia y la validez, véase BAscuñán, Antonio (1998) "El principio de distribución de competencia como criterio de solución de conflictos de normas jurídicas". Revista Chilena de Derecho, Número especial, p. 34.

26 BASCUÑán, Antonio (2000) "Sobre la distinción entre derogación expresa y derogación tácita”. Anuario de filosofía jurídica y social, ${ }^{\circ} 18$, p. 233.

27 Hart, Herbert (1998) El concepto de derecho. Traducción de Genaro Carrio. 2a ed., Buenos Aires: Abeledo Perrot, p. 119.

28 Von Wright (1970) p. 199. 
original y la norma que la niega no pueden ser ambas verdaderas ni falsas a la vez ${ }^{29}$-, corresponde afirmar que si el precepto en cuestión constituye una norma prohibitiva referida a una acción particular, su negación coresponde a la afirmación de un permiso relativo respecto de la acción originalmente prohibida ${ }^{30}$ : toda acción no prohibida se encuentra prescrita o absolutamente permitida ${ }^{31}$.

Luego, si los derechos corresponden naturalmente a permisos ${ }^{32}$, es decir, por regla general no imponen obligaciones a su titular, debemos entender que el permiso relativo debe concretarse en un permiso absoluto.

Estando ante un permiso, será fundamental determinar si este corresponde a lo que normalmente se denomina permiso débil, o permiso fuerte: volviendo a Von Wright, podemos decir que es necesario distinguir entre los actos que no han sido sometidos a norma, y los que sí. Estos últimos, a su vez, pueden estar prohibidos, mandados o permitidos; a diferencia de ellos, los que no se encuentran sometidos a norma están ipso facto noprohibidos, y en ese sentido se puede decir que están permitidos. De esta manera, los permisos que están sometidos a norma, son permisos fuertes; los permisos que no están sometidos a norma, son permisos débiles ${ }^{33}$.

Así las cosas, y habiendo en principio una norma que prohíbe la acción, debemos descartar la afirmación de un permiso débil, y entender que la inconstitucionalidad de la norma prohibitiva se funda en la exis-

29 Hruschka, Joachim (2005) "Sobre la utilidad del hexágono deontológico para el derecho". Traducción de Pablo Sánchez-Ostiz. En: Hruschka, Joachim, Imputación y derecho penal. Estudios sobre la teoría de la imputación. Navarra: Aranzadi S.A., p. 43. En términos similares: Воввіо, Norberto (1992) Teoría general del Derecho. Traducción de Eduardo Rozo. Bogotá: Temis, pp. 184 y ss.

30 Hruschka (2005) p. 47.

31 HruschKa (2005) p. 50.

32 VON WRIGHT (1970) p. 102.

33 Von Wright (1970) p. 101. En el mismo sentido: Bulygin, Eugenio (2009) "La importancia de la distinción entre normas y proposiciones normativas", pp. 3 y 4 . Disponible en:http://www.fcje.org.es/wp-content/uploads/file/jornada17/1_BULYGIN.pdf [fecha de consulta: 14 de enero de 2013]; Navarro, Pablo (2011) "Permisos, enunciados normativos y proposiciones normativas". XVII Seminario Hispano-Italiano-Francés de Teoría del Derecho (Getafe, 21-22 de octubre de 2011) (Getafe, Grupo de Investigación sobre el Derecho y la Justicia), p. 4. Disponible en: http://e-archivo.uc3m.es/bitstream/10016/13857/1/ permisos_navarro_SHIF_2011.pdf [fecha de consulta: 14 de enero de 2013]; RAZ (1991) p. 98. Si bien esa diferenciación es correcta, es posible complementarla: si volvemos al entendimiento de las normas como razones para la acción, la permisión de una acción puede explicarse de tres maneras: 1) por cuanto no hay razones para no realizar esa acción; 2) por cuanto habiendo razones para no realizar esa acción, hay una razón excluyente de esas razones, estando exigido no considerarlas; y 3) por cuanto habiendo razones no superadas para no realizar la acción, hay autorización para no tomar en cuenta esas razones, es decir, el destinatario puede no tomar en cuenta esas razones. En ese esquema, tanto el supuesto considerado en el $\mathrm{n}^{\circ}$ 2) como el del $\mathrm{n}^{\circ}$ 3), corresponden a permisiones fuertes (pp. 102 y 103). Así entendidas, todas las permisiones jurídicas son permisiones excluyentes, que permiten realizar el acto, y permiten no considerar razones para no realizar el acto (p. 166). 
tencia de un permiso constitucional fuerte de realización del acto legalmente prohibido.

En otros términos, si entendemos que los enunciados normativos corresponden a aquellos que tienen la forma " $\Phi$ debe, no debe o puede ser", entonces estos tendrán como resultado un estatus deóntico para una acción; y, si en conjunto con ello, afirmamos que las proposiciones normativas corresponden a la proposición de que una norma existe ${ }^{34}$, entonces las proposiciones normativas se encuentran entrańadas en los enunciados normativos, de forma tal que la afirmación de que una acción es obligatoria o prohibida, entraña la proposición normativa de que existe una norma que ordena o prohíbe esa acción -o que es razón para realizar esa acción o para omitirla-, aun cuando la existencia de esa norma no sea suficiente por sí sola para afirmar la existencia de la obligación o prohibición (ya que incluso existiendo la norma que ordena una conducta, esa acción igualmente puede no ser obligatoria por existir también una segunda norma en conflicto con la primera; pero en ningún caso podría la conducta ser obligatoria si no fuera verdadera la proposición normativa según la cual existe una norma que ordena o prohíbe la acción ${ }^{35}$ ).

Conforme a lo anterior, si se declarara la inconstitucionalidad de la norma que prohíbe, ello constituiría la afirmación del enunciado normativo puro ${ }^{36}$ "la acción $\Phi$ no está prohibida"; el cual (descartando que la acción esté ordenada) en principio puede entrañar dos proposiciones normativas distintas: o que "no hay norma que prohíba $\Phi$ en nuestro sistema jurídico", o que "hay una norma que permite $\Phi$ nuestro sistema jurídico" 37 . En este caso -y puesto que de seguro hay una proposición normativa conforme a la cual "hay una norma que prohíbe $\Phi$ "-, no puede no haber una proposición normativa afirmativa, por lo que si eventualmente se declara la inconstitucionalidad, con ello estaría afirmando la existencia de una permisión fuerte de jerarquía Constitucional, basada en una cláusula de derecho fundamental. Dicho con otras palabras, y siguiendo la terminología de Hohfeld ${ }^{38}$, del hecho que la Constitución no haga referencia a una acción $\Phi$ se sigue que constitucionalmente existe libertad de $\Phi$, la cual es correspondiente a la ausencia de deber de omitir $\Phi$ y correlativa al no derecho de terceros de impedir que el titular de dicha libertar realice $\Phi$. Ahora bien, la contradicción a la Constitución por parte de una norma legal que prohíbe $\Phi$ exige más que una simple libertad

Von Wright (1970) pp. 120 y 121; en el mismo sentido, NaVarro (2011) p. 1.

RAZ (1991) pp. 33 y ss.

Aquel respecto del cual la existencia de una norma es suficiente para hacerlo verdadero (RAZ (1986) p. 71).

37 Rodriguez, Jorge (2003) "Naturaleza y lógica de las proposiciones normativas. Contribución en homenaje a A. G. H. von Wright”. Doxa, n²6, pp. 97 y 98.

38 Hohfeld, W. H. (1992) Conceptos jurídicos fundamentales. 2a ed., Trad.: Carrió, Genaro, Fontamara S. A., México, pp. 50 y ss. 
constitucional de $\Phi$ : la antinomia no es entre una libertad constitucional y una prohibición legal, ambas respecto de $\Phi$ (si así fuera, solo podrían prohibirse legalmente las conductas respecto de las cuales ya existiera un deber de omisión en la Constitución, por lo que la prohibición legal sería redundante); sino que entre una prohibición legal de $\Phi$ y su correlativo jurídico, es decir, un derecho constitucional -o permisión constitucional fuerte- de la misma acción $\Phi$.

Por ello, la veracidad de la proposición normativa ya indicada -“existe una permisión constitucional fuerte de $\Phi "-$ y del enunciado normativo que la entraña - "hay una norma constitucional que permite $\Phi$ ”, depende, justamente, de la existencia de dicha norma permisiva ${ }^{39}$.

Para juzgar si esa norma existe, es indispensable analizar el enunciado legal que le daría origen, y aquí es donde la manera en que están redactados los derechos fundamentales resulta determinante, generando en ciertos casos efectos precisamente contrarios a los que el neoconstitucionalismo sostiene.

Una de las características de este fenómeno constitucional es tender a una sobreinterpretación de la Constitución, conforme a la cual ella regula derechamente toda la vida política y social ${ }^{40}$, de manera que las decisiones legislativas se encuentran siempre prerreguladas constitucionalmente ${ }^{41}$, entendiendo así que su texto es -al igual que las demás fuentes escritas- base directa para la construcción normativa ${ }^{42}$. Así las cosas, en principio parece posible sostener que la flexibilidad de las disposiciones constitucionales da un amplio margen al Tribunal Constitucional ${ }^{43}$. En palabras de Dworkin, el que se trate de estándares vagos y genéricos tendría como consecuencia que para poder ser aplicados, el juez debe concretarlos ${ }^{44}$.

\footnotetext{
39 Von Wright (1970) p. 121; Raz (1986) p. 71.
}

40 Prieto, Luis (2001) "Neoconstitucionalismo y ponderación judicial". AFDUAM, n 5, p. 208; Villacorta, Luis (2011) "Jurisdicción constitucional y derechos fundamentales. Aspectos a destacar en la discusión espańola”. Ius et praxis, $n^{\circ} 1$, año 17, p. 94.

41 Guastini, Riccardo (2003) "La constitucionalización del ordenamiento jurídico: el caso italiano”. Traducción de José María Lujambio. En: Carbonell Sánchez, Miguel (coord.) Neoconstitucionalismo (s). México: Trotta, p. 54.

42 Aldunate, Eduardo (2010) "Aproximación conceptual y crítica al neoconstitucionalismo". Revista de Derecho, Vol. 23, n 1, p. 88, Prieto (2001) p. 204 y 205, habla de "Constituciones normativas garantizadas". Igualmente Cea indica que la Constitución resulta obligatoria sin necesidad de que la ley medie entre sus valores, principios y normas y los destinatarios (CeA, José Luis (2008) Derecho Constitucional Chileno. Tomo I. 2a ed., Santiago: Ediciones Universidad Católica de Chile, p. 244; también en CEA, José Luis (2006) "Es Tribunal Constitucional y el control de la leyes”. En: CEA, José Luis Escritos de Justicia Constitucional, Santiago: LOM Ediciones, p. 105.).

43 Mac-Clure, Lucas (2011) "Tribunal Constitucional y los derechos: la discusión pendiente". En: Sierra, Lucas; Mac-Clure, Lucas, Frente a la mayoría: leyes supramayoritarias y Tribunal Constitucional en Chile. Santiago: CEP, CIEPLAN y Libertad y Desarrollo, Proyectamérica, p. 238.

44 Véase: Fernández, José Ángel (2010) "El juicio constitucional de proporcionalidad de la leyes penales: ¿La legitimación democrática como medio para mitigar su inherente irracio- 
Pero, jes eso efectivo? Acá se sostendrá que lo relevante para el análisis normativo es determinar si la redacción de los derechos fundamentales contiene, explícita o implícitamente, la especificación de una acción, aún genérica, que pueda ser objeto de una permisión. Veremos que, al contrario de lo que se señala por el neoconstitucionalismo, la forma en que se contemplan los derechos fundamentales llevará en muchos casos a impedir que se pueda afirmar una permisión a partir de ellos. Para abordar este punto, nos resultará útil seguir el trabajo de Searle sobre filosofía del lenguaje.

Así, podemos distinguir diversos géneros de actos del habla, los cuales son posibles gracias a reglas para el uso de elementos lingüísticos ${ }^{45}$. De esta forma, al emitir palabras, el hablante está realizando actos de emisión; al referir y predicar, está realizando actos proposicionales; y al aseverar, preguntar, ordenar, está realizando actos ilocucionarios ${ }^{46}$. Conjuntamente con ello, los efectos del acto ilocucionario sobre el oyente están referidos al acto perlocucionario ${ }^{47}$. Vistas así las cosas, el enunciado legal del tipo penal -que corresponde a un acto de emisión-, puede ser entendido como acto ilocucionario de prohibición, por cuanto, al emitir la oración "el que acceda carnalmente a otro mediante violencia será castigado", es posible considerar que se cumplen las condiciones necesarias para que el acto de prohibir haya sido realizado exitosamente ${ }^{48}$. Entre estas condiciones se cuenta el que la emisión debe predicar un acto futuro, lo cual sirve para constituir la "condición de contenido proposicional" 49 .

Ahora bien, más allá de la dificultad de calificar las permisiones dentro de una categoría particular de actos del habla $a^{50}$, para que el acto de permitir se realice de manera exitosa, es igualmente necesario que en la

nalidad?". Revista de Derecho Universidad Católica del Norte, año 17, n 1, p. 71; igualmente Nogueira, Humberto (2005) "El control represivo concreto y abstracto de inconstitucionalidad de las leyes en la reforma de las competencias del Tribunal Constitucional y los efectos de sus sentencias". Estudios Constitucionales, n 1 , ańo 3, p. 18.

45 Searle, John (2007) Actos del habla. Ensayo de filosofía del lenguaje. Traducción de Luis Valdés Villanueva. 6ª ed., Madrid: Ediciones Cátedra, pp. 25 y 26.

46 De forma tal que todo acto locucionario necesariamente conlleva la realización de un acto ilocucionario (SEarle, John (1968) "Austin on locutionary and illocutionary acts". The Philosophical Review, Vol. 77, $\mathrm{n}^{\circ}$ 4, p. 412).

47 SeArle (2007) pp. 32 y ss., conforme a lo cual los actos proposicionales no pueden ocurrir nunca solos, sino que siempre que se refiere y predica algo, se está acertando, ordenando o preguntando, es decir, realizando un acto ilocucionario (p. 34).

SeARle (2007) p. 62.

SEARLE (2007) p. 65.

Véase a modo de ejemplo: Hierro, José (1986) Principios de filosofía del lenguaje. Madrid: Alianza Editorial, pp. 324 y ss., quien niega que una permisión pueda clasificarse en la misma categoría de los mandatos, y Stiles, William (1993) "Clasificación de actos ilocutivos intersubjetivos". Anuario de Psicología, n 59, p. 80 y 85, quien los incluye como un acto que busca influir la conducta de otro. 
emisión se predique un acto futuro respecto del destinatario ${ }^{51}$, ya que si entendemos que las permisiones jurídicas corresponden a permisiones excluyentes -es decir, permiten tanto realizar el acto como no considerar razones para no realizar el acto $^{52}$-, entonces en la misma medida que las prohibiciones y los mandatos, ellas solo pueden ser tales si es que a partir de su acto de emisión es posible individualizar, al menos, un acto futuro en concreto. Solo así se cumplirá con que el acto permitido por la disposición permisiva sea una instancia del acto prohibido por la disposición prohibitiva ${ }^{53}$; lo que es obviamente coincidente con el entendimiento de que el elemento "contenido" es común a las normas obligatorias y permisivas.

En esos términos, la contradicción de una norma prohibitiva o de mandato respecto de la acción $\Phi$ con una cláusula de derecho fundamental, requiere que esta última, entendida como acto proposicional, predique el mismo acto que la norma prohibitiva o de mandato, lo que significa que la disposición de derecho fundamental debe "plantear la cuestión" de “ $\Phi$ " respecto del sujeto normativo ${ }^{54}$. Y ello podría tener lugar si se describe la acción concreta, o si ella se encuentra implícita en la emisión.

Así, por ejemplo, si alguien permite jugar fútbol, está permitiendo todos los actos permitidos por el fútbol, sin que sea necesario, al realizar la emisión, especificar todos esos actos ${ }^{55}$. Esto es especialmente relevante cuando lo que se permite consiste en un hecho social, los cuales -a diferencia de los hechos brutos, que existen con independencia de las instituciones humanas- requieren de instituciones para existir. Las instituciones, por su lado, son tales en virtud de la existencia de reglas constitutivas, las cuales disponen que $X$ cuenta cómo $Y$ en $C^{56}$, de forma tal que el término $Y$ tiene que asignar un estatus (funcional) que no se posee previamente por la sola satisfacción de ser $X^{57}$. En esta medida, en la base de las instituciones se encuentra en la cooperación humana (esto es, en la "imposición

\footnotetext{
51 SEARLE, John (1976) "A classification of illocutionary acts". Language in society, Vol. 5, $\mathrm{n}^{\circ} 1$, p. 11; también RAZ (1991) p. 109.

52 Raz (1991) p. 166; en el mismo sentido: Raz (1986) pp. 205 y ss.: la idea de que un acto permitido es un acto "no guiado", requiere en los mismos términos que una prohibición, la concreción del acto permitido.

53 RaZ (1986) pp. 207.

54 SeARle (2007) pp. 128 y ss.

55 Al respecto, véase: SeArle (2010) pp. 102 Y 103.

56 Searle, John (1997) La construcción de la realidad social. Traducción de Antoni Domenech. Barcelona-Buenos Aires: Paidós, pp. 45 y 46; igualmente en SEArle, John (2010) Making the social world. The structure of human civilization. New York: Oxford University Press, p. 13 y 99 y ss.: en ella se afirma que en términos generales toda creación de realidad institucional descansa en la declaración de que un estatus funcional $Y$ existe, es decir, son posibles instituciones en las que no exista un algo $(X)$ que cuente como $Y$, sino que derechamente se cree un estatus funcional "encima" de nada. Sobre la distinción entre constitución y regulación, véase: Atria, Fernando (2001) On Law and legal Reasoning. Oxford: Portland Oregon, pp. 20 y ss.

57 SeArle (1997) p. 62.
} 
colectiva de función”), por cuanto se asignan funciones que no pueden ser cumplidas atendiendo solo a propiedades físicas del mundo empírico: los hechos brutos pasan a indicar algo que va más allá de ellos ${ }^{58}$.

\subsection{1) El efecto de la indeterminación}

Es en este punto en el que la naturaleza abstracta y genérica con que las Constituciones formulan algunos derechos fundamentales se constituye en un obstáculo a la hora de afirmar su vulneración por parte de preceptos legales. Ello ocurre con derechos tales como la "libertad de expresión", "vida privada" o la "igualdad ante la ley" 59.

Supongamos una norma legal que prohíbe realizar una determinada conducta $\Phi$, y que ella se objeta aduciendo que con ello se vulnera el derecho a la vida privada. Para determinar si ello es correcto, se debe definir si ese derecho confiere una permisión de realizar esa acción.

Así, correspondiendo la vida privada a un hecho social, se podría argumentar que el acto de emisión conforme al cual "se asegura a todas las personas el respeto y protección a la vida privada” entraña la permisión de todos los hechos -brutos y sociales- que cuentan como "vida privada". Pero en ese punto surgirá la pregunta sobre qué actos específicos integran ese hecho social.

Claro, si ello estuviera regulado por el Derecho, entonces el problema desaparecería: el Derecho, justamente, lo que hace es reducir contingencia permitiendo la cooperación y posibilitando los contactos anónimos ${ }^{60}$. Siguiendo un modelo funcional ${ }^{61}$, podemos entender que la sociedad, en tanto institución normativa, ve determinada su identidad en función de reglas de configuración ${ }^{62}$ constitutivas de expectativas normativas eventualmente contrafácticas que, en esa medida, adelantan el

SEARle (1997) pp. 56 y 57.

A modo de ejemplo, Dworkin, Ronald (1999) Freedom's Law. Cambridge, Massachusetts: Harvard University Press, p. 7.

60 Atria, Fernando (2003c) "Ubi, ius, ibi remedium? La relevancia jurídica de los derechos humanos". Revista de Estudios de la Justicia, n 3, p. 39.

61 Al respecto, véase: Szczaranski, Federico (2012) "Sobre la evolución del bien jurídico penal: un intento de saltar más allá de la propia sombra”. Politica Criminal, Vol. 7, n 14, pp. 405 y ss.

62 Jаковs, Günther (2000) Sociedad, norma y persona en una teoría de un derecho penal funcional. Traducción de Manuel Cancio y Bernardo Feijoo. Madrid: Editorial Civitas, p. 26. La sociedad tendrá lugar tan pronto como la relación con otro se defina por al menos una regla independiente de las preferencias individuales que sea posible invocar (p. 79). Solo cuando dicha regla tenga realidad social, la sociedad será también real; en: JAKOBs, Günther (2006) Terroristas como personas en derecho. Traducción de Manuel Cancio. Disponible en: http:// neopanopticum.wordpress.com/2008/08/30/\%c2\%bfterroristas-como-personas-en-derechog-jakobs/ [fecha de consulta: 14 de enero de 2013]. 
comportamiento del otro e informan lo que se espera de cada uno ${ }^{63}$; con lo que la persona misma pasa a corresponder igualmente a una entidad determinada por normas ${ }^{64}$. Con ello, mi relación con otro es posible sin necesidad de conocerlo, ya que puedo confiar en que se comportará de la forma en que las normas disponen que se comporte.

La característica del Derecho que permite esto es justamente su autoridad: siendo que necesitamos para el desarrollo de la vida social el establecimiento de patrones de conducta, y que los distintos miembros de la sociedad podemos discrepar respecto de los esquemas adecuados, el Derecho sirve para delimitar cuándo una opinión sobre la forma adecuada de coordinación es ya no opinión particular, sino que ha pasado a ser obligatoria para todos, con independencia de cualquier opinión particular ${ }^{65}$, y constituye una regulación autoritativa ${ }^{66}$. Esto significa que deja de ser relevante, para el juicio conforme a Derecho, lo que cada uno cree que es la forma correcta de comportarse en un determinado contacto social, por cuanto esa determinación ya ha sido definida.

Trasladando esta autoridad a los hechos sociales, y entendiendo que la "intencionalidad colectiva" 67 es lo que hace de puente entre la realidad empírica y la sociedad ${ }^{68}$, el Derecho evita que la interacción dependa del juicio de cada uno sobre esa intencionalidad colectiva: si es nuestro reconocimiento colectivo lo que determina que algo cuente como un hecho institucional, y en esa medida define los poderes deónticos que se entrañan en ese estatus funcional, entonces -en principio- la identificación de las acciones prohibidas y ordenadas requiere identificar qué deontología es reconocida por los miembros de una comunidad; es decir, para saber si una acción está ordenada, se requeriría saber si acaso en un determinado contexto, esa comunidad entiende que esa acción está ordenada ${ }^{69}$. Ahora bien, ese proceso de identificación de la intencionalidad colectiva se simplifica mediante la formalización del derecho. Así, si hay regulación autoritativa, entonces no es relevante la discusión entre distintas concepciones particulares del concepto en cuestión, es decir, ya no es necesario preguntarse qué es lo que -conforme a la intencionalidad colectiva-cuenta como un hecho institucional, puesto que ello ya habría sido determinado.

\footnotetext{
63 Feijoo, Bernardo (1997) El injusto penal y su prevención ante el nuevo código penal de 1995. Madrid: Editorial Colex, 143 p. 53

64 Jаковs, Günther (2003) Sobre la normativización de la dogmática jurídico-penal. Traducción de Manuel Cancio y Bernardo Feijoo. Madrid: Editorial Civitas, pp. 19 y 20.

65 Raz, Joseph (1985a) La autoridad del derecho. Ensayos sobre derecho y moral. Traducción de Rolando Tamayo y Salmorán. 2a Ed., México: Universidad Nacional Autónoma de México, p. 71.

$66 \quad$ Raz (1985a) p. 72.

67 Sobre las "we-intentionality", véase: SEARLE (2010) pp. 49 y ss.

68 Searle (1997) p. 58.

69 SeARle (2010) p. 102.
} 
Ello significa que si la Constitución definiera los hechos comprendidos bajo el concepto de "vida privada", e incluyera a $\Phi$ entre ellos, entonces no cabría más que aceptar que la Constitución permite ese acto.

El problema, justamente, es que las Constituciones raramente llegan a especificar qué hechos cuentan como ejercicio de la "vida privada" o de la "libertad de expresión". Por ello, ante la duda respecto de lo que se debe considerar como integrante de este hecho, "quien busque la respuesta no debería malgastar su tiempo buscándola en el DL 3464 que consagra los (polémicos) derechos a la vida y a la vida privada. Si la atención se fija ahí, lo que se encuentra (...) es una zona de incertidumbre constitucional"70.

Y ello no significa que para la aplicación del precepto constitucional este deba ser concretado por el intérprete; sino que significa, simplemente, que la Constitución al referirse a la vida privada, no contempla ninguna permisión de una acción que no pueda identificarse sin consideración a la opinión del adjudicador. Así, se afirma que en los actos ilocucionarios se logra lo que con ellos se intenta en el momento en el cual el oyente reconoce lo que estamos tratando de hacer; es decir, logramos saludar diciendo "hola", cuando el oyente comprende que está siendo saludado, justamente gracias a que conoce el significado de la emisión "hola"71. Para que ello sea posible, la emisión debe estructurarse mediante vehículos convencionales socialmente reconocidos, cuya producción es regularmente entendida por los intervinientes como transportadora de ciertos significados ${ }^{72}$. Si esto es correcto, entonces ello supone que la emisión misma debe tener un significado que va más allá de la opinión del oyente. Es este significado "objetivo" el que permite que las normas sirvan como estándar, pauta o criterio de conducta ${ }^{73}$, ya que para cumplir esta función, lo que ellas prescriben debe identificarse con independencia de la perspectiva del destinatario, puesto que de lo contrario el destinatario tendría a su disposición lo reglado, sin que se pudiera determinar ex ante el comportamiento adecuado, ni ex post enjuiciarlo como antinormativo ${ }^{74}$, con lo que el Derecho deja de servir a la coordinación social de contactos anónimos. Por lo mismo, si el estatus deóntico de una acción como jurídicamente exigida se impone como resultado del acto del habla consistente en

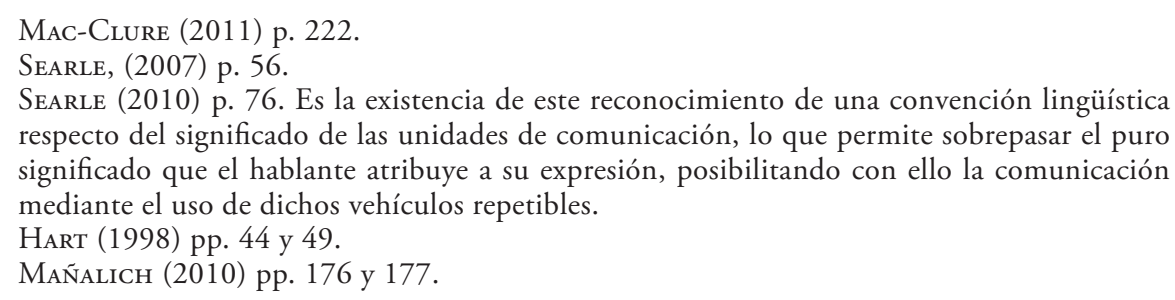


su promulgación ${ }^{75}$, entonces dicha acción deberá estar definida ya en la emisión de ese acto $^{76}$.

Ello significa que si se argumenta que una conducta es el contenido de una permisión (no judicial, sino que) constitucional fuerte, entonces dicha conducta debe ser identificable con independencia de la opinión -por razonable y bien fundada que se encuentre-, ya sea del sujeto normativo (caso en el cual no habrá permisión), ya sea del juez (caso en el cual habrá permisión judicial); sino que debe poder identificarse en el mismo acto constitucional de emisión ${ }^{77}$. Solo en ese caso tendrá sentido hablar de contradicción con la Constitución. De esta forma, el hecho que el juez tome en cuenta el texto constitucional a efectos de determinar una acción permitida, no basta para afirmar que esa permisión sea constitucional, por cuanto ello solo tendrá lugar en la medida que sea posible afirmar que la Constitución, entendida como acto del habla, identifica con independencia de la perspectiva del adjudicador, aquella acción como permitida. Dicho con otras palabras, si las normas se comprenden como expresión de deseo relativo a una acción ${ }^{78}$, entonces, en la medida que no es el significado de las palabras "vida privada" el que designa la acción referida, sino que esa determinación está dada por el juicio del adjudicador, entonces la norma referida a esa acción concreta no puede ser atribuida, en principio, a una expresión de deseo de la Constitución, sino que del juez: ha sido justamente la vaguedad de los términos utilizados lo que ha impedido que el significado de los mismos identifique un comportamiento permitido.

Podría intentar forzarse aún más el punto, y -siguiendo una línea similar a la de Dworkin en El imperio de la justicia- sostener que la labor judicial está definida por la integridad, de forma tal que los derechos y deberes que el ordenamiento impone no se deben restringir a los que se encuentran expresamente consagrados, sino que se deben determinar suponiendo que todos fueron creados por un mismo autor que expresa una correcta concepción de justicia y equidad; de forma tal que el Derecho refleje un conjunto coherente de principios de justicia que lo fundamen$\tan ^{79}$. De esta forma, - podría continuar el argumento- se deben considerar permitidas aquellas conductas que sea coherente con el resto del orde-

\footnotetext{
75 Mañalich, Juan Pablo (2012) "Reglas primarias de obligación. Las reglas del derecho penal en el concepto de derecho de H. L. A. Hart”. Zeitschrift für Internationale Strafrechtsdogma$t i k, \mathrm{n}^{\circ} 11$, p. 583 .

76 Lo cual no requiere, a su vez, que la emisión consista en una oración que exprese esa acción: si al ver a un hijo cruzando la calle con luz roja, el padre grita “¡No!”, la emisión “¡No!” igualmente identifica la acción "cruzar con luz roja".

77 En términos relativamente similares: WaLdron, Jeremy (1999b) The Dignity of Legislation. Cambridge: Cambridge University Press, p. 158.

$78 \quad$ HaRT (1998) p. 53.

79 Dworkin, Ronald (2005) El imperio de la justicia. Traducción de Claudia Ferrari. Barcelona: Editorial Gedisa S.A., pp. 137 y 164.
} 
namiento que se encuentren permitidas. En este esquema, lo central para la determinación de lo permitido está determinado por la coherencia que dicha permisión ofrece con la totalidad del ordenamiento jurídico.

Pero con esta línea argumental no se puede llegar muy lejos en aquellos casos en los que la Constitución no ofrece suficiente material jurídico como para afirmar que hay un principio de justica que dota de contenido a aquellas cláusulas de derechos fundamentales que son especialmente abstractas: si entendemos que el conjunto de todos los enunciados normativos puros de un mismo sistema jurídico describe totalmente a ese sistema jurídico ${ }^{80}$, y consideramos a la Constitución como un sistema jurídico independiente - por cuanto no se puede concretar un términos constitucional abstracto haciendo referencia a una precisión de rango legal, para luego utilizar el término concretado de esa manera para alegar una contradicción entre constitución y ley-, entonces si al interior de ese conjunto de enunciados no es posible establecer relaciones respecto de un concepto abstracto utilizado en uno de ellos, tampoco es posible afirmar que la Constitución contempla un principio de justicia que define el contenido de una cláusula abstracta.

Ello ocurre, por ejemplo, con la libertad de expresión o la vida priva$\mathrm{da}^{81}$ : en la Constitución chilena ese término solo se menciona una vez en todo el texto constitucional y es imposible definir una dirección habiendo solo un punto de referencia. Ese problema se podría salvar si la Constitución, en alguna otra cláusula, hiciera referencia a la misma acción que la norma legal; en ese caso, podría buscarse apoyo en esas otras cláusulas Constitucionales para determinar un estatus deóntico de jerarquía constitucional. Pero si ello no ocurre, entonces la Constitución se encuentra con el problema de Brandom: es imposible manejar solo un concepto ${ }^{82}$, ya que el dominio de uno consiste justamente en dominar algunas de sus relaciones inferenciales con otros ${ }^{83}$, comprometiéndose así el emisor con las inferencias que van desde sus condiciones de aplicación hasta sus consecuencias $^{84}$. Luego, si la Constitución no hace más referencias a la vida privada, entonces ¿cómo podría entenderse que ella, y no el adjudicador, afirma un principio que permite concretar dicho término?

Por ello, al referirse la Constitución a la "vida privada" sin que sea posible establecer, ni en base al entendimiento generalizado del término, ni en función de una definición autoritativa, una relación entre ella

\footnotetext{
$80 \quad$ RAZ (1986) pp. 71.

81 A lo que se podría agregar que tampoco la cultura jurídica provea criterios suficientes como para precisar esos contenidos (Mac-Clure (2011) pp. 239 y ss.).

82 Brandom, Robert (2001) Articulating reasons. An introduction to inferentialism. Cambridge, Massachusetts, London: Harvard University Press, p. 15

83 BRANDOM (2001) p. 49.

$84 \quad$ BRANDOM (2001) p. 70.
} 
y la conducta legalmente prohibida, entonces no puede afirmarse que la Constitución autorice ese comportamiento, siquiera implícitamente.

Si la inconstitucionalidad supone afirmar un enunciado de subsunción, es decir, requiere la instanciación de un universal (la conducta permitida constitucionalmente) en un particular (la conducta prohibida legalmente $)^{85}$, la indeterminación del derecho fundamental impide dicha subsunción.

Es distinto, por supuesto, el caso respecto de derechos fundamentales redactados de manera más precisa, en los cuales sí es posible afirmar -ya sea por el significado de las palabras utilizadas en la cláusula concreta, o por cuanto la Constitución misma se refiere suficientemente a ellos en otras partes de su texto- una acción particular como su contenido; de forma tal que en la medida que esa acción particular coincida con el contenido de la norma legal, será posible sostener la inconstitucionalidad.

\section{2) INCONSTITUCIONALIDAD POR PROCEDIMIENTO: INFRACCIÓN DE DERECHO FUNDAMENTAL EN DICTACIÓN DE LA DISPOSICIÓN LEGAL}

El problema que acá se presenta no radica en una incompatibilidad entre la norma legal y la constitucional de derechos fundamentales, sino que tiene lugar por cuanto en la dictación de la norma legal no se ha ejercido correctamente el poder normativo que ha generado la disposición jurídica de rango legal ${ }^{86}$, infringiéndose en ese momento un derecho fundamental.

El caso paradigmático se encontrará referido a la prohibición constitucional de establecer diferencias arbitrarias. Este derecho fundamental corresponde ser entendido como prohibiendo al legislador tratar de manera diferente casos semejantes, o dar un trato arbitrario mediante ley. Ello significa que con independencia de si existe una norma constitucional incompatible con la norma legal dictada, la norma legal será inconstitucional por infringir la prohibición referida.

Pero, una vez más, el obstáculo se encuentra en la indeterminación de la prohibición que se establece al legislador.

Al igual que en la inconstitucionalidad por contenido, afirmar la inconstitucionalidad por procedimiento también requiere afirmar un enunciado de subsunción, realizándose entonces un juicio prescriptivo conforme al cual conducta del legislador queda comprendida en la extensión del la norma prohibitiva de derecho fundamental: no realizar diferencias ar-

\footnotetext{
85 Mañalich, Juan Pablo (2005b) "El concurso de delitos: base para su reconstrucción en el derecho penal de Puerto Rico". Revista Jurídica UPR, Vol. 74, pp. 1001 y ss.

86 Sobre las normas que confieren poderes, véase: Raz (1991) pp. 114 y ss.
} 
bitrarias. Luego, es necesario identificar en la emisión constitucional una acción respecto de la cual sea posible afirmar, sin recurrir a la valoración $u$ opinión del adjudicador, que la acción del legislador es una instancia particular. Por lo mismo, la indeterminación del derecho fundamental impide la subsunción. De esta forma, se debe identificar la acción del legislador como una acción que constitucional, y no judicialmente, cuenta cómo o "arbitraria”. Luego, si la Carta Fundamental no contempla material jurídico como para asegurar una definición de dicho término que incluya en su extensión a la acción legislativa ${ }^{87}$, entonces no podemos identificar la prohibición de esa acción en el acto constitucional de emisión, y resulta entonces imposible afirmar la inconstitucionalidad.

De esta forma, si respecto de "vida privada" no era posible afirmar la inconstitucionalidad ya que no era posible afirmar una permisión constitucional de la conducta legalmente prohibida, respecto de la "igualdad", la inconstitucionalidad no puede determinarse si no es posible afirmar una prohibición constitucional de la acción particular del legislador.

Así, mientras que la afirmación "en un grupo de 100 la mayoría se alcanza con 49" es señal de que el emisor no entiende el significado de mayoría lo mismo no puede decirse de alguien que sostenga que "la disposición legal en cuestión no constituye una instancia de arbitrariedad". Por ello, se solucionaría el problema si fuera posible afirmar una definición autoritativa de estos términos, pero la ausencia de material jurídico que permita sostener la existencia de una definición de este tipo determina finalmente que la constatación de esa contradicción depende de una valoración que no se encuentra definida en el texto constitucional, ni por el significado que podríamos llamar "natural y obvio" de las palabras, ni por una especificación legal. En este caso, entonces, no puede haber contradicción a la Constitución.

Por supuesto, no se trata de sostener que desconocemos el significado de "arbitrario" o "vida privada": sabemos el tipo de consideraciones que son relevantes a la hora de utilizar esas palabras ${ }^{88}$, pero $-y$ esto es lo esencial- con eso no basta para afirmar la contradicción a la Constitución. Ella requiere específicamente que las disposiciones legales en cuestión constituyan una instancia particular de "vida privada" o "arbitrario"; y en base solo al significado de las mismas no es posible afirmar esto.

\footnotetext{
87 Obviamente, no se puede recurrir al material jurídico de jerarquía legal para completar el material jurídico insuficiente de jerarquía constitucional (así, véase Correa, Rodrigo (2005) "Vulgarización por constitucionalización". Derecho y humanidades, n 11, p. 165; NogueIRA, Humberto (2009b) "Enfoques sobre interpretación constitucional y Jurisdicción constitucional”. En: Pfeffere, Emilio (Coord.) Temas actuales de Derecho Constitucional. Libro homenaje a Mario Verdugo Marinkovic, Santiago: Editorial Jurídica de Chile, pp. 157). SeArle (2007) pp. 17.
} 


\section{3) LA ALTERNATIVA}

En contra de lo acá defendido se pueden encontrar una serie de teorías que parecen poner el acento en que la corrección del juicio de constitucionalidad depende de la razonabilidad y correcta motivación y argumentación ${ }^{89}$ de la sentencia que resuelve la revisión judicial, llegándose incluso a defender por Martínez y Zúniga, que razonabilidad es sinónimo de constitucionalidad ${ }^{90}$.

De esta forma, se argumenta que el análisis normativo es inadecuado respecto de algunos derechos fundamentales, por cuanto la Constitución debe ser entendida como un "todo orgánico", y en esa medida, el sentido y significado de sus distintas cláusulas debe determinarse de forma tal que exista armonía entre ellas ${ }^{91}$. Hasta cierto punto, esta idea es similar a la defendida por Dworkin en "El imperio de la justicia", en que se sostiene que la interpretación de una determinada cláusula se debe adaptar al resto del ordenamiento, por lo que el juez debe seguir la opción que sea más coherente con los principios de justicia que puedan armonizar con las demás disposiciones legales ${ }^{92}$. O, como explica Alexy, la idea de unidad de la Constitución se corresponde con la posibilidad de que las cláusulas constitucionales se delimiten mutuamente 93 .

Ahora bien, puesto que la armonización de distintas cláusulas, o la adecuada delimitación entre ellas, supone identificar un criterio independiente de las mismas, en función del cual las cláusulas son armonizadas o

89 Así, por ejemplo, los profesores Nogueira, Humberto (2009a) "Las mutaciones de la Constitución producidas por vía interpretativa del Tribunal Constitucional. El Tribunal Constitucional ¿poder constituido, o poder constituyente en sesión permanente? Estudios Constitucionales, $\mathrm{n}^{\circ}$ 2, año 7, p. 400 y ss., Fernández (2010) pp. 91 y ss., Lopera, Gloria (2011) "Principio de proporcionalidad y control constitucional de las leyes penales. Una comparación entre las experiencias de Chile y Colombia”. Revista de Derecho, Vol. XXIV, ${ }^{\circ}$ 2, p. 114. Zúńiga describe esto como la creencia en que la racionalidad nos puede llevar a la verdad, y que en consecuencia, no es la verdad misma; en ZúñIGA, Yanira (2010) "El principio de proporcionalidad como herramienta de proporcionalidad. Un análisis crítico de su aplicación en la jurisprudencia del Tribunal Constitucional chileno". Ius et Praxis, $\mathrm{n}^{\circ} 2$, año 16 , p. 251.

90 MartíneZ, José Ignacio; ZúñIga, Francisco (2011) "El principio de razonabilidad en la jurisprudencia del Tribunal Constitucional”. Estudios Constitucionales, n 1, año 9, p. 206.

91 Valenzuela, Eugenio (2006) Criterios de hermenéutica constitucional aplicados por el tribunal constitucional: Contribución del Tribunal Constitucional a la institucionalización democrática. Santiago: LOM, pp. 24 y ss.; Fernández, Miguel Ángel (2009) "Conflictos entre Derechos Fundamentales en la jurisprudencia del Tribunal Constitucional”. En: Pfeffer, Emilio (Coord.) Temas actuales de Derecho Constitucional. Libro homenaje a Mario Verdugo Marinkovic, Santiago: Editorial Jurídica de Chile, pp.77; Nogueira (2009b) p. 159.

92 Para un análisis crítico de la teoría de Dworkin, desde la tesis de las fuentes, véase: RAZ (1985b), pp. 307 y ss.

93 Alexy, Robert (2000) "Derecho injusto, retroactividad y principio de legalidad penal. La doctrina del Tribunal Constitucional Federal alemán sobre los homicidios cometidos por los centinelas del muro de Berlín”. Traducción de Daniel Oliver-Lalana. Doxa, n²3, p. 217. 
delimitadas, se podría recurrir a la finalidad de la Constitución -consistente en garantizar la libertad del hombre ${ }^{94}$ - como el criterio rector de la armonización; o utilizar, por ejemplo, a la totalidad del ordenamiento Constitucional para justificar dicha armonización ${ }^{95}$. El problema con estos intentos es que, o nos llevan al principio, por cuanto su aplicación requiere resolver el contenido de la "libertad del hombre", es decir, otro término genérico y abstracto; o, carecen de base constitucional para efectuar la armonización en aquellos casos en los que la Constitución menciona solo una vez el término que requiere ser armonizado, ya que si el texto no establece ninguna relación entre dos derechos, entonces la armonía o delimitación que se afirme estará siendo impuesta desde fuera.

\subsection{1) Ponderación}

Para hacer esto más claro, prestemos atención a una teoría muy difundida ${ }^{96}$ conforme a la cual ciertas cláusulas de derechos fundamentales no corresponden a reglas, sino que a principios, por lo que su forma de aplicación no es mediante la subsunción ${ }^{97}$, sino que requerirían ser "ponderados", significando que los mandatos derivados de ellos "valen relativamente con respecto a las posibilidades fácticas y jurídicas de su cumplimiento", debiendo cumplirse en la mayor medida posible.

Ello significa -en lo que acá interesa y en términos simplificados ${ }^{98}$ que ante un caso constitucional, en que se juzga la adecuación a la Constitución de una determinada medida, acción o ley; se debe analizar en que magnitud esa acción favorece un principio constitucional y en qué magnitud afecta negativamente a otro, siguiéndose para ello la regla de la ponderación, conforme a la cual a mientras más insatisfacción a un principio signifique la adopción de la medida, mayor deberá ser la importancia del favorecimiento del principio opuesto.

Para poder realizar ese juicio, entonces, es menester determinar en el caso concreto una "relación de precedencia condicionada" 99 entre los

\footnotetext{
94 Valenzuela (2006) p. 28; igualmente, Nogueira (2012) pp. 249 y 250.

95 Zapata, Patricio (2008) Justicia constitucional: Teoría y práctica en el derecho chileno y comparado. Santiago: Editorial Jurídica de Chile, pp. 395 y ss.

96 Nogueira, Humberto (2006) "El derecho a la igualdad ante la ley, la no discriminación y acciones positivas”. AFDUDC, n 10 , p. 813 y ss.

97 Alexy, Robert (2008) "La fórmula del peso". Traducción de Carlos Bernal Pulido. En: Carbonel, Miguel (Edit.) El principio de proporcionalidad y la interpretación constitucional. Quito: Ministerio de Justicia y derecho humanos, p. 15.

98 El modelo plantea dividir el análisis en tres pasos: definir el grado de afectación de un principio, la importancia de la satisfacción del principio contrario y finalmente determinar si esa importancia justifica la afectación del primer principio (Alexy (2008) p. 15).

99 Alexy, Robert (1993) Teoría de los derechos fundamentales. Traducción de Ernesto Garzón. Madrid: Centro de Estudios Constitucionales, pp. 91 y ss.
} 
principios constitucionales en juego, definida en parte por el "peso"100 de cada uno de ellos para la Constitución. Considerando ese peso, debe estimarse la magnitud (leve, media o grave) en que la acción a juzgar incide negativamente en el mismo y compararla con la importancia del principio opuesto $^{101}$.

Pero una vez más, el problema con este camino radica en que su aplicación tampoco permite afirmar la contradicción a la Constitución: el proceso de ponderación requiere comparar en el caso concreto la intensidad de una intervención determinada en un principio, con la importancia del principio contrario ${ }^{102}$. Ahora bien, si como señala Prieto, ambos principios en abstracto -es decir, en el texto constitucional- valen lo mismo $^{103}$, pero el resultado final debe hacer prevalecer a uno, entonces es necesario afirmar un criterio independiente de la Constitución para resolver el conflicto, ya que si la Constitución no da mayores especificaciones sobre el contendido o valor relativo del derecho, entonces la determinación de su peso, importancia o relación de precedencia respecto de otro, no puede descansar en la Constitución misma ${ }^{104}$.

Siendo ello así, nada obsta a que la afirmación que hace el juez sobre el peso de un principio sea, efectivamente, una afirmación razonable y bien fundamentada ${ }^{105}$. Pero que esa valoración sea racional no significa que la misma esté establecida en la Constitución. Tal como señala Bernal Pulido, la determinación del peso abstracto del principio depende de la

100 Para un completo análisis de la proporcionalidad en el juicio de constitucionalidad. Véase FERNÁNDEZ (2010) pp. 51 a 99.

101 Alexy (2008) p. 26 y ss. Todo lo cual constituye un modelo que Prieto denomina de "discrecionalidad débil" y que requiere considerar "imparcialmente los aspectos contrapuestos de una cuestión"; en PRIETo (2001) p. 210 y 211. De esta forma se afirma que bajo ciertas condiciones, un principio tiene precedencia sobre otro, lo que significa que en esos casos la acción en cuestión lesiona el derecho fundamental, estando prohibida por la Constitución. Ello importa entender que esas condiciones establecen el supuesto de hecho de una norma cuya consecuencia es jurídica es la determinada por el principio que resulta preferido bajo esas mismas condiciones (en: Alexy (1993) pp. 93).

102 Alexy (2008) p. 27.

103 Prieto (2001) p. 212.

104 En este sentido Aldunate (2010) p. 96: "si los valores que se sostienen presentes en el documento constitucional cumplen su función normativa al ser involucrados como tales en el juicio de ponderación, las razones en virtud de las cuales opera la preferencia condicionada en la que consiste el juicio de ponderación son independientes de tales valores y, por tanto, se encuentran del todo desvinculadas de la fuente jurídica de la decisión”. Así se pronuncian ARnold, Rainer; Martínez, José Ignacio; Zúñiga, Francisco (2012) "El principio de proporcionalidad en la jurisprudencia del Tribunal Constitucional". Estudios Constitucionales, $\mathrm{n}^{\circ} 1$, ańo 10 , p. 85 ; quienes no obstante no advierten que la falta de parámetro para "pesar" es equivalente a la falta de "razón" para definir la proporcionalidad.

105 El que se trate de un juicio sobre valores no obsta a su discusión sea razonable, e incluso sus conclusiones puedan consideradas "objetivas". Al respecto, fundamental el trabajo de Putnam, Hilary (2002) The collapse of the fact/value dichotomy and other essays. Cambridge, Massachusetts, London: Harvard University Press, 190 pp. 
mejor teoría sustancial del juez sobre la Constitución, y ante ello la Constitución misma no da ninguna respuesta correcta ${ }^{106}$. Que a continuación agregue que ello no reduce la racionalidad del procedimiento ${ }^{107}$, o que se diga que el juicio de ponderación o proporcionalidad es defendible como uno de carácter racional ${ }^{108}$ o bien fundamentado ${ }^{109}$, no quita el que la resolución del caso no puede comprenderse como la resolución que la Constitución da al caso ${ }^{110}$. Siguiendo en esto a Aldunate, cada vez que se ejercita la ponderación, el juez está atribuyendo sentido a un texto jurídico a partir de sus valores personales, las cuales no se exponen directamente como su opción personal, sino que como uno de los elementos que justifican la atribución de significado; lo que permite afirmar que es el texto el que funda una norma, cuando en realidad ella descansa en sus propias opciones ${ }^{111}$.

Vistas así, estas teorías buscan determinar márgenes constitucionales que limiten la discrecionalidad del juzgador a la hora de concretar derechos fundamentales abstractos ${ }^{112}$, pero esos mismos límites propuestos parecen carecer de igualmente de la concreción necesaria para efectivamente limitar. Lo que ello significa es que la determinación del contenido del derecho fundamental, si bien se resuelve racionalmente considerando la Constitución, no puede entenderse como propia de la misma Constitución, sino que responde a la valoración del juzgador.

106 Bernal Pulido, Carlos (2008) “La racionalidad de la ponderación”. En: Carbonel, Miguel (Edit.) El principio de proporcionalidad y la interpretación constitucional. Quito: Ministerio de Justicia y derecho humanos, pp. 65 y 66.

107 Bernal Pulido (2008) p. 68.

108 Alexy, Robert (2006) “Ponderación, control de constitucionalidad y representación”. Traducción de René de la Vega. En: Ibáñez, Perfecto; Alexy, Robert, Jueces y ponderación argumentativa. México: Universidad Nacional Autónoma de México, 2006.

109 Nogueira (2006) p. 811.

110 Esto es hecho explícito por Alexy al afirmar que el resultado de la ponderación consistente en un "enunciado de preferencia sobre una relación de precedencia condicionada se sigue una regla que prescribe la consecuencia jurídica del principio que tiene preferencia cuando se dan las condiciones de preferencia" (ALEXy (1993) p. 94); es decir, la resolución "constitucional" del caso, requiere la formulación de una norma (que Alexy denomina regla) cuyo supuesto de hecho se obtiene mediante valoraciones del juez que no depende la Constitución misma.

111 Aldunate, Eduardo (2002) "Interpretación, valores y sistema constitucional”. Cuadernos de derecho público, $\mathrm{n}^{\circ} 15$, p. 85 .

112 Así, Nogueira señala que el Tribunal Constitucional no tiene permitido resolver de manera irracional o arbitraria, sino que por el contrario, su interpretación de la Constitución debe encontrarse correctamente motivada y basarse en enunciados normativos, ser universalizable y reconocer los principios y valores del orden constitucional (NogueIra (2009a) p. 399). Igualmente Breyer, quien hace presente que los jueces se encuentran restringidos por las reglas y principios de la práctica judicial, que la misma experiencia impone restricciones, que ellos ven efectivamente a la Constitución como un marco, que exista un "tejido" jurídico que condiciona las decisiones, etc. (Breyer, Stephen (1999) "Revisión judicial: la perspectiva de un juez”. Traducción de Fernando Atria, Estudios Públicos, n 75, p. 56 y ss.) 
Ello resulta evidente en la medida que el método propuesto permite agregar a la regla 103.2 de la Ley Fundamental, que establece la prohibición de retroactividad de la ley penal (!), una cláusula inexistente en el texto constitucional, que exceptúa su aplicación en caso de "un Estado injusto que ampara un derecho extremadamente injusto"113, justificándose en que la irretroactividad (cuya consagración no hace referencia a excepción alguna) corresponde a una manifestación del principio del estado de derecho, el cual incluye exigencias relativas a la justicia material que colisiona con el principio opuesto de la seguridad jurídica, y que "también derecho ilimitables pueden ser limitados, conforme al principio de proporcionalidad, siempre que así lo exijan 'derechos fundamentales de terceros' u otros valores jurídicos dotados de rango constitucional". Por supuesto, nada impide que se pueda argumentar razonablemente sobre la corrección de una limitación de ese tipo en caso de los centinelas del muro de Berlín, pero ello no significa que la cláusula agregada sea una cláusula constitucional.

Lo paradójico de todo esto, es que así como se ha indicado que respecto una cláusula que reconozca la "igualdad ante la ley" resulta difícil afirmar que ha sido infringida por un acto concreto de legislación; ello no ocurre con un caso como el defendido por Alexy: parece evidente que ahora sí es posible concebir varias acciones, ya sean del legislador o de los tribunales, que pueden constituir una instancia particular de la acción prohibida por el 103.2 de la Ley Fundamental114: "penar una acción cuya punibilidad no estuviera establecida con anterioridad a la comisión del acto"; sin que para realizar el juicio de subsunción se deba recurrir a nada más que al significado de las palabras empleadas por el texto constitucional.

\subsection{2) La ley de la libertad para Dworkin}

Ante este escenario, el gran mérito de "Freedom's Law", continuando la línea de "Los derechos en serio" y alejándose de la teoría interpretativa de "El imperio de la justicia"115, es justamente reconocer de manera abierta que, entendiendo así el problema, la Constitución no establece mayores límites al juez ${ }^{116}$. Por el contrario, se sostiene que la única forma

113 Cláusula que Alexy defiende como "claramente definida" (Alexy (2000) pp. 215).

114 El cual dispone: "Derecho a ser oído, prohibición de leyes penales con efectos retroactivos y el principio de ne bis in idem. (2) Un acto solo podrá ser penado si su punibilidad estaba establecida por ley anterior a la comisión del acto".

115 Para un análisis de las diferencias centrales que son posibles encontrar entre ambas líneas de trabajo de Dworkin, véase: Atria, Fernando (2011) "Lo que importa sobre los principios". En: Carbonell, Flavia; Letelier, Raúl; Coloma, Rodrigo (coord.), Principios jurídicos. Análisis y critica, Santiago: LegalPublishing Chile, pp. 65 a 90.

$116 \mathrm{Al}$ respecto Atria hace presente que al expresarse conceptos (es decir, formulaciones abstractas de una idea) y no concepciones, si se le solicita al juez que resuelva en consideración a 
que para que la Corte pueda hacer cumplir lo que dice la Constitución, es si el juez toma sus propias decisiones sobre esos conceptos abstractos ${ }^{117}$ : los términos amplios de la Constitución "can only be applied to concrete cases through fresh moral judgments" ${ }^{118}$, de forma tal que en los casos constitucionales concretos el intérprete debe preguntarse por la forma en que esos principios morales abstractos son mejor entendidos, lo que supone que la resolución del conflicto dependerá de las convicciones del juez relativas a las virtudes morales ${ }^{119}$.

Es decir, Dworkin hace explícita esa realidad que otras teorías buscan ocultar: la resolución judicial del caso constitucional, en lo que se refiere a derechos fundamentales consagrados en términos abstractos, descansa en la valoraciones morales del juez.

Ello se explica por cuanto Dworkin, al hacer frente al modelo hartiano de derecho -conforme al cual este está compuesto únicamente de reglas, las cuales solo pueden aplicarse de forma mecánica (en los casos claros correspondientes al núcleo duro de la norma) o con discreción fuerte (en los casos que se encuentran en la penumbra de la norma) ${ }^{120}$ - extiende el ámbito de lo que se reconoce como Derecho, afirmando que en él se incluye no solo su contenido explícito, sino que también el esquema de principios necesario para justificar las reglas positivas ${ }^{121}$.

De esta forma, se incluyen como parte integrante del Derecho a los principios, los cuales corresponden a un estándar que debe ser observado por ser una exigencia de la justicia, la equidad o alguna otra dimensión de la moralidad ${ }^{122}$, y cuyo reconocimiento como parte del Derecho no depende de su consistencia con una norma de reconocimiento, sino que de un sentido de conveniencia y oportunidad que, tanto en el foro como en la sociedad, se desarrolla con el tiempo ${ }^{123}$. En esta medida, y a diferencia de las reglas, los principios corresponden a un estándar que no puede aplicarse mecánicamente, sino que requieren siempre un ejercicio de discernimiento por parte del juez.

Luego, sostiene Dworkin, en los casos difíciles, el tribunal debe argumentar demostrando que la resolución adoptada sirve para asegurar un

ellos él deberá no podrá sino complementar ese concepto que todos compartimos, y concretarlo en su propia concepción de ese concepto, con lo cual ya no será imparcial, sino que aliado de una de las partes (Atria, Fernando (2003a) "El derecho y la contingencia de lo político". DOXA, n 26 , p. 331 y ss.)

117 Dworkin, Ronald (1989) Los derechos en serio. Traducción de Marta Gustavino. 2a ed., Barcelona: Editorial Ariel, pp. 215 y 216.

118 DwOrkin (1999) p. 3.

119 DWORKIN (2005) p. 180.

120 Atria (2011) p. 66.

121 DWORKIN (2005) p. 164

122 DWORKIN (1989) p. 72

123 Dworkin (1989) pp. 94 y 95; Riddall, J.G. (1999) Teoría del Derecho. Traducción de TsEdi, Teleservicios Editoriales, S.L., Barcelona: Editorial Gedisa, p. 145 
derecho ${ }^{124}$, el cual no puede ser derrotado apelando a objetivos ordinarios de la administración ${ }^{125}$.

En este modelo, los casos constitucionales se resuelven mediante lo que el autor denomina "lectura moral de la Constitución", conforme a la cual aquellos derechos fundamentales incluidos en la Constitución como estándares vagos, es decir, formulados de manera muy amplia y abstracta ${ }^{126}$; deben ser entendidos como estableciendo un determinado concepto (libertad, igualdad, justicia) que requiere - para ser aplicado- que el juez desarrolle una concepción particular sobre él. Así, una pura referencia al concepto abstracto de igualdad no basta para desarrollar un programa de acción gubernamental ${ }^{127}$, puesto que una formulación abstracta de una idea puede dar cabida a concepciones incluso opuestas sobre la misma, de forma tal que aun cuando todos estemos de acuerdo en que no se deben realizar diferencias arbitrarias, igualmente discutiremos respecto de "qué semejanzas y qué diferencias entre las personas son pertinentes para determinar deberes y derechos" 128 .

Por ello, en virtud de la formulación abstracta de los derechos fundamentales, todo juicio de revisión judicial supone un juicio moral fresco para poder ser llevado a cabo ${ }^{129}$.

La lectura moral, entonces, favorece que los jueces lean la Constitución a la luz de sus propias convicciones morales, haciendo explícitos los juicios morales en los que sus interpretaciones descansan, permitiendo así que el público participe. El texto y la integridad limitan, pero no eliminan el impacto de las convicciones morales del juez a la hora de aplicar Derecho $^{130}$.

124 Dworkin (1989) p. 148; Dworkin, Ronald (1985) A matter of principle. Cambridge, Massachusetts, London: Harvard University Press, p 11.

DWORKIN (1989) p. 161.

DWORKIN (1999) p. 2

127 HaYeK, Friedrich (1980) “El ideal democrático y la contención del poder”. Estudios públicos, $\mathrm{n}^{\circ} 1$, p. 39.

128 Rawls, John (1995) Teoría de la Justicia. Traducción de María González. 2a ed., México: Fondo de cultura económica, p. 19.

129 DWORKIN (1999) p. 3.

130 Dworkin (1999) p. 37. Si la validez de la ley depende no solo de su forma de producción, sino que también de su coherencia con principios constitucionales, entonces el juez podrá dejar de aplicar la ley si ella no se condice con los valores constitucionales, los cuales, a su vez, no son dependientes del mismo texto de la Constitución, sino de la que sea, según el juez, la mejor lectura moral posible de la Constitución; y ello significa que si lo que va a primar es un orden moral, entonces la Constitución misma depende de él para ser válida (Aldunate (2010) p. 93). Así, Tremblay, Luc (2003) "General legitimacy of judicial review and the fundamental basis of constitutional law". Oxford Journal of Legal Studies, Vol. 23, $\mathrm{n}^{\circ} 4$, p. 554. Igualmente, SANT'ANA (2012) p. 385, quien hace ver que, aun cuando el texto de la Constitución disponga que la familia se constituya por "el casamiento", en razón de las mudanzas en las concepciones culturales y sociales brasileñas, se trata como familia también a la pura convivencia. 
De esta forma, Dworkin reconoce abiertamente que en los juicios de revisión judicial la Corte hace cumplir la Constitución tomando sus propias decisiones sobre esos conceptos ${ }^{131}$. Con ello, Dworkin puede ser considerado un referente de los intentos de la ética legalista ${ }^{132}$ por intensificar su presencia en la vida política, entendiendo que hay normas que, ya estando $a h i^{133}$ (es decir, antes de la política), pueden servir de barrera a la acción del legislador, el cual -en tanto representante de la política democrática- es visto como potencial enemigo de los derechos fundamentales ${ }^{134}$.

El problema normativo con el camino de Dworkin ${ }^{135}$-e implícitamente de los defensores del juicio de ponderación o razonabilidad-, parece ser que la lógica de las normas solo permite que una norma de rango legal contradiga la Constitución en caso que ella contenga una norma incompatible con aquella, y si eso es así, los "principios" resultan irrelevantes: las normas no pueden contradecirlos a menos que ellos sean

131 DWORKIN (1989) p. 216.

132 Shklar, Judith (1968) Legalismo. Traducción de Isabel Giménez. Buenos Aires: Bibliográfica Omeba, 237 pp.

133 ShKLAR (1968) p. 22.

134 Atria, Fernando (2003b) "La hora del derecho: los 'derechos humanos' entre la política y el derecho”. Estudios Públicos, n 91, p. 65. Al respecto, véase también НАYEK (1980) p. 47 y Sierra, Lucas (2012) "Quórum legislativo de supramayoría y Tribunal Constitucional en Chile”. SELA 2012. Pappers and Programs, pp. 6 y 7. Disponible en: http://www.law.yale. edu/documents/pdf/sela/SELA12_Sierra_CV_Sp_20120409.pdf [fecha de consulta: 14 de enero de 2013].

135 En este punto no podemos abordar adecuadamente las críticas que pueden levantarse desde la teoría política. No obstante ello, se hace presente que un sistema ideado para alcanzar los "mejores resultados" interpretativos (Dworkin (1985) p. 24; Villacorta (2011) p. 100. Una idea hasta cierto punto similar parece ser defendida por Ruiz-Tagle, Pablo (2005) "La vulgarización como eslogan y los derechos fundamentales". REJ, n 11, p. 156) desconoce que justamente, de lo que estamos discutiendo, es acerca de aquello que cuenta como "mejor resultado" (Waldron, Jeremy (1999a) Law and Disagreement. New York: Oxford University Press, pp. 242 y 243): es precisamente porque hay desacuerdo sobre la corrección de las decisiones, que necesitamos establecer y reconocer una autoridad (WALDron, (1999a) p. 245). En la misma línea, la desformalización en procesos judiciales tiene un costo que va más allá de la simple pérdida de utilidad que importa el no tener que indagar los méritos sustantivos del caso (los cuales se encuentran especialmente bien explicitados en AтrYAH, Patrick (1986) Essays on contracts, Clarendon Press, Oxford, Cap. 5); sino que importa una modificación del agente que realiza la valoración moral sustantiva: ya no es el legislador, el representante del pueblo, quien evalúa las razones sustantivas y decide una forma de comportamiento ante ellas, sino que ahora es un abogado. De esta manera, el camino dworkiniano puede fácilmente ser visto como parte del intento de la ética legalista por configurar las instituciones jurídicas de forma tal que sirvan de protección ante las decisiones políticas, se recurre a contenidos demasiado vagos como para resolver una situación política o moral concreta y específica (ShKLAR (1968) p. 113), con lo que no solo se sientan las bases para que en un mundo "complicado y poco orgánico" (SHKLAR (1968) p. 101) la decisión judicial resulte autoritaria -tal como lo advertía ya Bentham- sino que, peor aún, se olvida que no es el Derecho el que termina las guerras ni el que hace que se cumplan las normas (Shklar (1968) pp. 145 a 147. En sentido similar: Atria (2003a) p. 323: se sostiene que los Tribunales no son el tipo de institución que puede combatir el terror, ya que o lo apoyan -como en la Dictadura chilena- o los intervienen). 
concretados en una norma, pero en el modelo dworkiniano (o en el modelo de la ponderación como discreción débil) la forma en que el juez lleva a cabo esa concreción impide considerar que la norma resultante sea una norma de la Constitución, ya que dos jueces con valores político-morales distintos concretarán distintas normas ${ }^{136}$ que pueden ser incluso incompatibles entre sí. De esta manera, es justamente porque la norma no está en la Constitución que el juez debe afirmarla en base a su propio juicio moral, y por ello, no es posible hablar de contradicción a la Constitución.

Respecto del problema de la inconstitucionalidad por procedimiento, el resultado es el mismo: la indeterminación del derecho fundamental impide la instanciación de un universal en un particular.

Tomemos por ejemplo la afirmación de Nogueira: "En todos los aspectos relevantes, las personas deben ser tratadas y consideradas de igual manera, a menos que haya una razón suficiente para no hacerlo"137; o, como proponen Martínez y Zúniga respecto de la igualdad, se debe atender a que la diferenciación sea prudente y meditada, prohibiéndose solo las diferencias irracionales o arbitrarias ${ }^{138}$. En todos estos casos, la afirmación de que el caso concreto constituye o no una instancia particular de una de estas expresiones, es un ejercicio en el cual es el aplicador de la norma quien define lo reglado, haciendo por tanto imposible afirmar la vulneración de una norma constitucional, por cuanto la prohibición no es posible de ser identificada en el acto constitucional de emisión, sino que solo en el judicial.

Nogueira, por ejemplo, afirma que toda diferencia basada en una dimensión subjetiva es sospechosa de inconstitucionalidad, debiendo ser sometida a un riguroso análisis de razonabilidad y proporcionalidad ${ }^{139}$. Pero la determinación de la motivación de un precepto legal también es necesariamente ambigua. Supongamos una regulación legal que establece una diferencia de trato entre heterosexuales y homosexuales, proscribiendo las relaciones sexuales homosexuales entre un mayor y un menor de edad, pero permitiéndolas entre personas de distinto sexo ${ }^{140}$. El juicio de

En términos similares, véase: Aldunate (2010) pp. 96 y 97

Nogueira (2006) p. 806, agregando luego la idea de distinguir entre aquellos que se encuentran en la "misma situación".

MartíneZ; ZúŃIga (2011) p. 211.

Nogueira (2006) p. 804.

Un caso de esta características fue resuelto por el Tribunal Constitucional chileno, afirmando la constitucionalidad del precepto: Sentencia Tribunal Constitucional sobre Inaplicabilidad, 4 de enero de 2011, Rol n ${ }^{\circ}$ 1.683-10-INA. Para un detallado análisis sobre el caso, véase VV.AA. (2011) "La inconstitucionalidad del artículo 365 del Código Penal. Informe en derecho". REJ, $\mathrm{n}^{\circ} 14$, pp. 73 a 109. Para un completo estudio sobre los defectos de fallo que rechaza la inaplicabilidad del precepto impugnado, véase: Bascuñán, Antonio (2011) "La prohibición penal de la homosexualidad masculina juvenil (comentario a la sentencia del Tribunal Constitucional de 4 de enero de 2011, ROL 1683-2010)". Estudios Públicos, n ${ }^{\circ}$ 124, pp. 113 a 137. 
inconstitucionalidad pasa por determinar si la motivación de la norma es discriminar por orientación sexual, o si acaso la motivación es proteger a los menores de un daño que solo tiene lugar en caso de relaciones homosexuales. Claro, si esto se pudiera zanjar, entonces se podría argumentar derechamente la inconstitucionalidad del precepto por perseguir una finalidad ilegítima ${ }^{141}$. Pero, como Jakobs nos recuerda, si entiendo que la configuración social supone una determinada moral que ve a la homosexualidad como un pecado, entonces al castigar la homosexualidad no consideraré que estoy castigando la homosexualidad per-se; es decir, mi motivación no será la condición homosexual por sí misma, sino que entenderé que mi motivación es proteger la sociedad ${ }^{142}$. Dicho con otras palabras: la ambigüedad de "arbitrario" produce los mismos efectos que la ambigüedad de "vida privada" o de "libertad de expresión". Y que siempre se pueda argumentar racionalmente sobre el significado que debería darse a esos términos ${ }^{143}$, no obsta a que la determinación de ese significado concreto no se encuentra en la Constitución, y que por lo tanto el resultado de esa ponderación no permite afirmar una contradicción a dicho texto, lo que Nogueira reconoce al afirmar que no hay claridad respecto de cuando un trato diferenciado se encuentra prohibido "desde una perspectiva constitucional" 144 .

Ello significa que la incorporación de valores, o el juicio de ponderación, permiten incluir en la construcción de la norma decisiones que no están vinculadas al texto ${ }^{145}$. La lectura moral dworkiniana no hace sino reconocer y defender esa realidad. Lo relevante en este análisis no es (inmediatamente) la crítica política que se puede efectuar a ese modelo; sino la consecuencia normativa de que la norma se construya en base a decisiones independientes del texto constitucional: la norma resultante no puede ser entendida -justamente- como una norma constitucional.

\section{4) El Verdadero rol del Tribunal Constitucional}

Por lo anterior, y considerando la ausencia de especificación autoritativa de los derechos fundamentales, en este trabajo estamos defendiendo lo que Dworkin denomina una postura "pasivista"146 (y esencialmente deferente $^{147}$ ) respecto a la Constitución, y rechazamos que esta toma de

\footnotetext{
141 Fernández (2010) p. 77, y en general VV.AA. (2011).

142 Jаковs, Günther (2004) ¿Qué protege el derecho penal: bienes jurídicos o la vigencia de la norma? Mendoza: Ediciones Jurídicas Cuyo, p. 36 y ss.

143 Nogueira (2006) p. 810.

144 Nogueira (2006) p. 811

145 Aldunate (2002) p. 87.

146 DWORKIN (2005) p. 264.

147 Lascuraín, Juan Antonio (2012) “¿Restrictivo o deferente? El control de la ley penal por parte del Tribunal Constitucional”. InDret, 3/2012, p. 3
} 
posición pueda ser descartada en base a la integridad ${ }^{148}$, por cuanto se comparte la crítica del escepticismo interno que niega la posibilidad de coherencia -al menos respecto de algunos derechos fundamentales- en la Constitución ${ }^{149}$.

Vistas así las cosas, se revela la verdadera naturaleza de la declaración de inconstitucionalidad: se trata de un acto ilocucionario declarativo que afirma la existencia de la norma permisiva o prohibitiva ${ }^{150}$ (dependiendo si se trata de inconstitucionalidad de contenido o de procedimiento); y puesto que hasta antes de la inconstitucionalidad dicha norma no existía, entonces la resolución que declara la inconstitucionalidad crea la norma, ya que esa es la única forma de que el mundo se ajuste al contenido proposicional del acto del Tribunal.

Si lo anterior es efectivo, la idea generalizada de concebir el Tribunal Constitucional como un legislador negativo ${ }^{151}$ resulta ser falsa: al excluir una norma del Derecho, se está simultáneamente incorporando otra (la negación de la primera) al Derecho ${ }^{152}$.

\section{3) IMPLICANCIAS}

Antes de concluir el presente trabajo, es necesario hacer alguna mención a dos puntos que deben ser considerados en caso de aceptarse el mo-

148 DWORKIN (2005) p. 173.

149 Dworkin (2005) p. 192.

150 Más específicamente: el Tribunal, en la sentencia, establece un determinado estatus deóntico para $\Phi$. Si ese estatus deóntico corresponde a una prohibición o mandato, entonces necesariamente está afirmando la existencia de una norma que manda o prohíbe $\Phi$; mientras que si afirma que el estatus deóntico corresponde a una permisión, entonces en principio puede estar afirmando tanto la ausencia de una norma referida a $\Phi$ (en cuyo caso habrá una permisión débil de ), como la existencia de una norma que permite $\Phi$. Ahora bien, si el sistema jurídico contempla una norma que prohíbe, entonces la afirmación de que su estatus deóntico corresponde a una permisión, solo puede ser verdadera en caso de que exista igualmente una norma que permita $\Phi$.

151 Kelsen, Hans (1929) "La garantía jurisdiccional de la Constitución (La justicia constitucional)". Annuaire de l' Institut de Droit Public, p. 54. Disponible en: http://biblio.juridicas. unam.mx/libros/1/31/tc.pdf, 107 pp [fecha de consulta: 14 de enero de 2013]; igualmente Ruiz-Tagle, Pablo (2003) "La tesis de la doble pluralidad: jueces y democracia, el caso de la transición chilena 1990-2002”. En: Malem, Jorge; Orozco, Jesús; VÁzquez, Rodolfo (comp.) La función judicial. Ética y democracia. Barcelona: Gedisa, p. 277.

152 Ello debe considerarse en conjunto con que en el caso chileno "se ha seguido el camino brutal" de considerar los derechos fundamentales como fuente directa de normas prohibitivas (Bascuñán, Antonio (2007) "Derechos fundamentales y derecho penal". Revista de Estudios de la Justicia, $\mathrm{n}^{\circ}$ 9, p. 55), de forma tal que con ello el Tribunal Constitucional no solo afecta al titular del nuevo permiso (es decir, no solo se establece una tolerancia), sino que también se regulan relaciones del titular con terceros (Von Wright (1970) p. 104). Sobre la relación entre derecho fundamental y deberes de terceros, puede verse Nino, Carlos Santiago (1989) Ética y derechos humanos. $2^{\circ}$ Ed., Buenos Aires: Astrea de Alfredo y Ricardo Depalma, pp. 31 y ss. 
delo de revisión judicial acá propuesto, aun cuando el estudio completo de ambos va más allá del objeto de este artículo. Ellos dicen relación, en primer lugar, con la teoría del razonamiento jurídico compatible con esta aproximación, y en segundo término con un entendimiento no jurídico de los derechos fundamentales.

\section{1) RESPECTO DEL RAZONAMIENTO JURÍDICO}

El razonamiento jurídico busca contestar la pregunta sobre el modo de aplicar el Derecho una vez que aquel ha sido determinado. El problema que se plantea en este punto (en los términos de Von Savigny) es que si bien el sentido de la ley puede ser claro, el mismo puede simultáneamente no resultar coherente con el "pensamiento real de la ley", habiendo un defecto que dicho autor denominaba "expresión impropia"153. En ese caso se entendería que la ley no debe aplicarse al caso concreto, aun cuando este sí se encontrare comprendido en los términos claros de esta.

Lo que hemos afirmado hasta ahora solo hace referencia a la forma en que es posible extraer una norma a partir de una disposición jurídica, y no supone -como parece entenderlo Prieto ${ }^{154}$ - un compromiso con una teoría mecanicista de la adjudicación ${ }^{155}$ que sea ciega a las particularidades del caso, ordenando aplicar siempre la ley a todos los que caigan dentro de su tenor literal. Por el contrario, lo que en este trabajo se defiende es una forma de razonamiento legal que sea formal, pero no formalista ${ }^{156}$.

Acá solo estamos considerando a las normas de conducta como razones excluyentes para la acción, lo que es compatible con entender que las normas secundarias de adjudicación no determinan por sí solas la habilitación para aplicar la consecuencia jurídica ${ }^{157}$, sino que por el contrario, estas pueden concebirse como conllevando una cláusula ceteris pari-

153 Von Savigny, Friedrich (1878) Sistema del derecho romano actual, Tomo 1. Traducción de Jacinto Mesía y Manuel Poley. Madrid: F. Góngora y compañía, p. 161. La "textura abierta" de Hart busca justamente dar un margen de maniobra ante estos casos, entendiendo que la regla deja abierta para su solución ulterior aquellas cuestiones que solo pueden resolverse adecuadamente una vez que aparecen, mediante un compromiso que realiza el juez entre distintos intereses (HaRT (1998) pp. 161 y ss.).

154 Prieto (2001) p. 217.

155 Lo que es afirmado por Zapata (2008) p. 203; que da paso, a su vez, a una reductio ad hitlerum, al agregar -con referencias a PRECHT, nota al pie $\mathrm{n}^{\circ} 131-$, que ese formalismo se encuentra en las raíces del totalitarismo.

156 Sobre la distinción véase Атıунн (1986) pp. 93 y ss.: se indica que tiene razón Raz al señalar que la norma no busca constituirse en una razón más para la acción, sino que por el contrario, busca reemplazar la demás razones, pero ese reemplazo tiene lugar dentro de ciertos límites, cuyo reconocimiento evita el formalismo.

157 Ello significa que si se siguiera una concepción de la norma de sanción como una que impone deberes, entonces la inclusión de la cláusula ceteris paribus impide comprenderla como una razón excluyente para la acción: al menos no excluye todas las demás razones para la acción. 
bus $^{158}$ (o defeater ${ }^{159}$ ) que dispone la consecuencia normativa en los "casos normales" 160 , restando por ello todavía que el juez determine cuándo un caso es normal ${ }^{161}$. De esta forma, mientras que la norma de conducta es "no mates", la de sanción es "en casos normales, castíguese al que ha matado" 162 .

Ahora bien, ello plantea la necesidad de compatibilizar esta determinación por parte del juez con la necesidad de que la decisión correcta del caso pueda ser identificable con independencia de la perspectiva del adjudicador.

Una alternativa para ello puede ser el entender que el mismo Derecho define tácitamente qué características hacen de un caso uno normal, de manera tal que la especial capacidad técnica del juez es poder reconocer, mediante el estudio de la generalidad del Derecho, qué es lo que aquel ${ }^{163}$ considera normal. Así las cosas, se lograría que lo que constituye lo anormal (la excepción) sea de naturaleza jurídica, al igual que la norma misma ${ }^{164}$, no obstante lo cual, no es la misma norma la que define lo que es anormal (o el grado de formalidad con que ella debe ser aplicada) ${ }^{165}$.

158 Mañalich, Juan Pablo (2007) “La pena como retribución”. Estudios Públicos, n¹08, p. 189.

159 Moresco, Juan José (2008) "El positivismo jurídico, la interpretación del derecho y la aplicación de la Constitución”. Derecho y Humanidades, n 14, p. 48.

160 Atria, Fernando (2004a) "Jurisdicción e independencia judicial: el Poder Judicial como poder nulo”. REJ, n5, pp. 131 y ss. Igualmente Atria (2001) pp. 136 y 177.

161 Sobre la derrotabilidad, fundamental: Tur, Richard (2001) "Defeasibilism". Oxford Journal of legal Studies, Vol. 21, n² 2, pp. 355 a 368. Igualmente, véase: Maccormick, Neil (2005) Rhetoric and the rule of law. A theory of legal reasoning. Oxford University Press: Oxford, Capítulo 12;

En una línea que puede considerarse similar, véase: Silva (2010) p. 581. Por ello, es un error considerar que al no aplicar la consecuencia en un caso anormal se está desconociendo el derecho (como parece entenderlo Alegre, Marcelo (2005) "Vulgarización y deterioro del derecho democrático". Derecho y Humanidades, n 11, p. 183).

162 Si ello se aceptara, entonces decae la diferencia esencial que se postula por (entre otros) Dworkin y Alexy entre reglas y principios (Dworkin (1989) p. 76; Alexy (1993) pp. 86 y 87; Alexy, Robert (2010) "The construction of constitutional rights". Law \& ethics of human rights, Vol. 4, Issue 1, p. 21), ya que las reglas no pueden aplicarse mecánicamente en un "todo o nada".

163 Esto se correspondería con lo que Dworkin denomina "rule-book conception" del estado de derecho; en: Dworkin (1985) p. 13.

164 Atria (2001) p. 124

165 Atria (2001) pp. 94 y 200. Utilizando ejemplos tradicionales: si el Derecho sanciona el ingreso de vehículos a un memorial de veteranos de guerra, y unos veteranos ingresan un camión de combate a dicho memorial, entonces para saber si este es un caso normal, el juez debería (a modo de ejemplo) considerar si el Derecho, en general, reconoce en otras normas un estatus especial a los veteranos, y si la respuesta es positiva, entonces tendrá una razón para decir que el Derecho -y no él- considera este caso en particular como uno anormal, por lo que no corresponde aplicar la consecuencia jurídica. De la misma manera, en el caso del barbero que por descuido derrama una gota de sangre en la calle, el juez debe preguntarse si el Derecho en general reconoce una diferencia entre causar un daño y no causarlo, o si en general sanciona duramente el ensuciar la calle; en base a lo cual puede decir que para el Derecho en este caso hay circunstancias relevantes que lo hacen anormal; por el contrario, 
Si se siguiera una línea como esta, el mismo proceso deberá realizar el juez con todos los términos abiertos que el Derecho emplea: deberá concretarlos en base a lo que él considera que es el entendimiento del Derecho de esos términos. Pero para ello, -y esto es lo que falta en el caso del los derechos fundamentales consagrados mediante términos abstractos- será necesario que efectivamente exista más material jurídico que permita realizar esa concreción ${ }^{166}$.

Cuando ese material jurídico exista ${ }^{167}$, entonces será posible comprender que al afirmarse que un caso particular es anormal, el juez emplea un concepto entrelazado (es decir, un concepto que describe y a la vez constituye un juicio de valor ${ }^{168}$ ), el cual en su faz normativa constituye un juicio de valor no básico (es decir, un juicio respecto del cual una revisión de los hechos en los que se funda abre la puerta a una modificación del juicio ${ }^{169}$ ), que se apoya en el hecho de que el Derecho regula de cierta manera ciertos supuestos. De esta perspectiva, el paso que realiza el juez,

si esas diferencias no se encuentran en el Derecho, entonces el resultado podrá ser absurdo para el juez, pero no lo será para el Derecho. Por lo demás, en una democracia representativa se espera que las valoraciones sociales se plasmen en el derecho, y por lo tanto, si el juicio del juez según el cual un resultado es absurdo, es un juicio compartido por la ciudadanía, entonces ello deberá verse reflejado en el derecho. Luego, cuando ello no ocurre, no nos encontramos ante un defecto del derecho, sino que del sistema político. A eso nos referiremos en el último apartado. Para Atria, en todo caso, la imposibilidad de determinar la aplicación de la norma al caso concreto se extiende a todo el material legal y no solo a la norma en cuestión (p. 201); razón por la que se propone considerar a la "imagen del derecho" como el elemento central en la determinación de lo que hace a un caso uno anormal: ello dependerá entonces del conjunto de creencias sobre la naturaleza del derecho que determinan los argumentos que se deben considerar al decidir la aplicación de un precepto (p. 220). En términos similares: Sinva, Jesús (2008) "La interpretación de la leyes y la cultura de los juristas". En: Montealegre, Eduardo; Caro John, José (edit.) El sistema penal normativista en el mundo contemporáneo: Libro homenaje al Profesor Günther Jakobs en su 70 aniversario. Bogotá: Universidad Externado de Colombia, 2008, pp. 213.

166 Así, por ejemplo, si hubiera suficiente material jurídico disponible, a partir del derecho a la vida privada se podría afirmar una norma de conducta que, como razón excluyente para la acción, prohíbe publicar fotos íntimas sin consentimiento del involucrado; al mismo tiempo que en base a la misma podría ser posible sostener la existencia de una norma secundaria respecto de la cual al juez le tocará determinar cuáles casos son normales, y qué significa "íntimo" para el derecho. Si siguiéramos los términos de MacCormick, de lo que se trata es de interpretar cada universal utilizado por la ley según el propósitos del derecho y del sentido de justicia "apropiado al campo jurídico en cuestión", lo que solo puede realizarse examinando el resto del material jurídico que configura ese campo (Массовміск, Neil (2007) "La argumentación silogística: una defensa matizada". Doxa. Cuadernos de filosofía del derecho, n³0, p. 329).

167 No es necesario sostener acá que la inexistencia de ese material jurídico signifique necesariamente la irracionalidad de una concreción por parte del juez del derecho a la vida privada (Alexy intenta explicar cómo el principio de proporcionalidad permite una racionalidad en la ponderación; en: Alexy (2010) pp. 26 y ss.); sino que esa concreción judicial no sirve para afirmar una contradicción a la Constitución.

168 Putnam (2002) pp. 32 y ss., y 62 y ss.

169 Sen, Amartya (1967) "The Nature and Classes of Prescriptive Judgments". The Philosophical Quarterly, Vol. 17, No. 66, p. 50. 
desde el enunciado normativo puro a la afirmación del enunciado normativo aplicativo, si bien no es mecánico, sí podría entenderse como objetivo ${ }^{170}$. Dicho de otra forma: siempre las valoraciones morales del juez -o su sentido de proporcionalidad o razonabilidad- jugarán, de hecho, un papel en el razonamiento jurídico; pero ello no obsta que sea posible entender que, conforme a derecho, la determinación de lo "anormal" se encuentra definida por el derecho mismo en los casos de sistemas en que hay suficiente material jurídico.

\section{2) RESPECTO DE LOS DERECHOS FUNDAMENTALES}

Si lo anteriormente dicho es correcto, entonces parecería que un derecho fundamental como la vida privada solo podría ser contrariado por un precepto legal si el contenido proposicional del segundo corresponde a una negación del contenido proposicional del primero; o si la ley prohibiera una acción que, con independencia de la perspectiva del adjudicador, forma parte de la extensión de la vida privada según el "sentido natural y obvio" de esos términos. Así las cosas, el rol en la práctica legal de aquellos derechos fundamentales cuya redacción impide identificar una acción, se verían drásticamente reducidos.

Esa reducción, en todo caso, no es tan distante de la que parece posible extraer del trabajo de $S c h m i t t^{171}$ o de la teoría de Kelsen, quien afirma que en los casos en los que la Constitución habla de justicia, libertad o igualdad, sin precisarlas mayormente, el legislador y los órganos de ejecución de la ley están autorizados a llenar discrecionalmente esos ámbitos, y solo si la Constitución indicara una dirección precisa, entonces esas disposiciones pueden entenderse como dando direcciones relativas al contenido de ley ${ }^{172}$.

En esta medida, el camino aquí propuesto parece adecuarse con mayor comodidad a un entendimiento de la Constitución como un hecho antes que Derecho, en la cual ella es resultado de la decisión de ejercer el

170 Putnam (2002) p. 94.

171 Schmitr, Carl (1996) Teoría de la Constitución. Traducción de Francisco Ayala. Madrid: Alianza Universidad Textos, 377 pp., parece llegarse a un resultado igualmente limitado, ya que si bien el autor indica que ni la ley ni la administración pueden contradecir los derechos fundamentales (p. 169), luego agrega que de ello no se sigue la imposibilidad absoluta de injerencias o limitaciones (p. 179); sino que de esa forma se establece únicamente que la necesidad de que las limitaciones a las libertades garantizadas por derechos fundamentales "solo pueden tener lugar a base de una ley, es decir, de una norma general, y mediante un acto de aplicación de una ley" (p. 181); entendiendo que la ley en el estado democrático de derecho debe ser manifestación de la voluntad popular -requisito democrático- y de carácter general -requisito del Estado de Derecho- (pp. 152 a 156).

Kelsen (1929) pp. 79 a 81. Igualmente en: Kelsen (1995) pp. 33 y 34. 
poder constituyente, mediante el cual el pueblo expresa su voluntad de existir en tanto comunidad política adoptando una forma particular ${ }^{173}$.

Si se sigue ese modelo, entonces la concepción de los derechos fundamentales que se encontraría implícita en el análisis normativo de constitucionalidad es una que los comprende, prioritariamente al menos, como principios sobre los cuales se apoya la unidad política del pueblo ${ }^{174}$, solo pudiendo jugar ese rol de unidad en tanto correspondan a conceptos generales capaces de albergar distintas concepciones; ya que si tienen esa cualidad, entonces son capaces de cumplir una función constitutiva indicando lo que es común a todos los ciudadanos, con lo que se hace posible la identidad de la comunidad ${ }^{175}$, pero impidiendo utilizarlos para resolver imparcialmente conflictos jurídicos.

Si esto es correcto, entonces los derechos fundamentales establecen límites políticos y no jurídicos. Ello importa que su infracción no acarrea efectos legales, pero sí puede significar el quiebre de la comunidad política. En esta medida, el modelo propuesto es compatible con una concepción schmittiana de lo político que no puede ser atada por el Derecho, ya que ambos se mueven en planos distintos: el clímax de nuestra separación, aquello que significa la negación de mi existencia, no es algo en lo que el código legal/ilegal tenga relevancia, ya que se trata de conflictos caracterizados justamente por cuanto no pueden ser resueltos recurriendo a una norma común, sino que deben ser resueltos directamente por los involucrados ${ }^{176}$.

\section{BIBLIOGRAFÍA}

- Aldunate, Eduardo (2002) "Interpretación, valores y sistema constitucional". Cuadernos de derecho público, n 15, pp. 77 a 90 .

- Aldunate, Eduardo (2010) "Aproximación conceptual y crítica al neoconstitucionalismo". Revista de Derecho, Vol. 23, n 1, pp. 79 a 102.

- Alegre, Marcelo (2005) "Vulgarización y deterioro del derecho democrático". Derecho y humanidades, n 11 , pp. 177 a 189.

\footnotetext{
173 Sснмітт (1996) pp. 93 y ss.

174 SсHмiтt (1996) p. 167.

175 Atria (2011) p. 77.

176 Schmitr, Carl (1998) El concepto de lo político. Traducción de Rafael Agapito. Madrid: Alianza Editorial, p. 57, agregando que no es nunca el derecho, sino que justamente los involucrados los únicos que pueden decidir cuando la existencia del otro pone en peligro la propia.
} 
- Alexy, Robert (1993) Teoría de los derechos fundamentales. Traducción de Ernesto Garzón. Madrid: Centro de Estudios Constitucionales, $607 \mathrm{pp}$.

- Alexy, Robert (2000) "Derecho injusto, retroactividad y principio de legalidad penal. La doctrina del Tribunal Constitucional Federal alemán sobre los homicidios cometidos por los centinelas del muro de Berlín". Traducción de Daniel Oliver-Lalana. Doxa, n² 23, pp. 197 a 230.

- Alexy, Robert (2006) "Ponderación, control de constitucionalidad y representación”. Traducción de René de la Vega. En: IBÁÑEz, Perfecto; Alexy, Robert, Jueces y ponderación argumentativa. México: Universidad nacional Autónoma de México, 2006, pp. 1 a 18.

- Alexy, Robert (2008) "La fórmula del peso". Traducción de Carlos Bernal Pulido. En: Carbonel, Miguel (Edit.) El principio de proporcionalidad y la interpretación constitucional. Quito: Ministerio de Justicia y derecho humanos, pp. 13 a 42.

- Alexy, Robert (2010) "The construction of constitutional rights". Law \& ethics of human rights, Vol. 4, Issue 1, pp. 20 a 32.

- Arnold, Rainer; Martínez, José Ignacio; ZúNiga, Francisco (2012) "El principio de proporcionalidad en la jurisprudencia del Tribunal Constitucional". Estudios Constitucionales, $\mathrm{n}^{\circ}$ 1, año 10, pp. 65 a 116.

- Atryah, Patrick (1986) Essays on contracts, Clarendon Press, Oxford, $396 \mathrm{pp}$.

- Atria, Fernando (2001) On Law and legal Reasoning. Oxford: Portland Oregon, 239 pp.

- Atria, Fernando (2003a) "El derecho y la contingencia de lo político". DOXA, n²6, pp. 319 a 347.

- Atria, Fernando (2003b) "La hora del derecho: los 'derechos humanos' entre la política y el derecho". Estudios Públicos, n 91 , pp. 45 a 89.

- Atria, Fernando (2003c) "Ubi, ius, ibi remedium? La relevancia jurídica de los derechos humanos". Revista de Estudios de la Justicia, $\mathrm{n}^{\circ} 3$, pp. 35 a 47.

- Atria, Fernando (2004a) "Jurisdicción e independencia judicial: el poder judicial como poder nulo". REJ, n 5, pp. 119 a 141 .

- Atria, Fernando (2004b) "La ironía del positivismo jurídico". $D O X A, \mathrm{n}^{\circ} 27$, pp. 81 a 139.

- Atria, Fernando (2011) "Lo que importa sobre los principios". En: Carbonell, Flavia; Letelier, Raúl; Coloma, Rodrigo (coord.), Principios jurídicos. Análisis y critica, Santiago: LegalPublishing Chile, pp. 65 a 90. 
- Bascuñán, Antonio (1998) "El principio de distribución de competencia como criterio de solución de conflictos de normas jurídicas". Revista Chilena de Derecho, Número especial, pp. 33 a 44.

- Bascuñán, Antonio (2000) "Sobre la distinción entre derogación expresa y derogación tácita". Anuario de filosofía jurídica y social, $\mathrm{n}^{\circ}$ 18, pp. 227 a 262.

- Bascuñán, Antonio (2007) "Derechos fundamentales y derecho penal". Revista de Estudios de la Justicia, n 9, pp. 47 a 74.

- Bascuñán, Antonio (2011) "La prohibición penal de la homosexualidad masculina juvenil (comentario a la sentencia del Tribunal Constitucional de 4 de enero de 2011, ROL 1683-2010)". Estudios Públicos, n 124, pp. 113 a 137.

- Bentham, Jeremy (1829) "Petition for Codification". En: Bentham, Jeremy, Justice and codification, London: Robert Heward, 9 pp.

- Bernal Pulido, Carlos (2008) "La racionalidad de la ponderación". En: Carbonel, Miguel (Edit.) El principio de proporcionalidad y la interpretación constitucional. Quito: Ministerio de Justicia y derechos humanos, pp. 43 a 68.

- Boвbio, Norberto (1992) Teoría general del Derecho. Traducción de Eduardo Rozo. Bogotá: Temis, 269 pp.

- Brandom, Robert (2001) Articulating reasons. An introduction to inferentialism. Cambridge, Massachusetts, London: Harvard University Press, 230 pp.

- Breyer, Stephen (1999) "Revisión judicial: la perspectiva de un juez". Traducción de Fernando Atria, Estudios Públicos, n 75 , pp. 49 a 66.

- Bulygin, Eugenio (2009) "La importancia de la distinción entre normas y proposiciones normativas", 7 pp. Disponible en:http:// www.fcje.org.es/wp-content/uploads/file/jornada17/1_BuLYGIN.pdf [fecha de consulta: 14 de enero de 2013].

- CEA, José Luis (2006) "El Tribunal Constitucional y el control de la leyes". En: Cea, José Luis Escritos de Justicia Constitucional, Santiago: LOM Ediciones, pp. 103 a 143.

- Cea, José Luis (2008) Derecho Constitucional Chileno. Tomo I. 2a ed., Santiago: Ediciones Universidad Católica de Chile, 406 pp.

- Correa, Rodrigo (2005) "Vulgarización por constitucionalización". Derecho y humanidades, ${ }^{\circ} 11$, pp. 161 a 175.

- Dworkin, Ronald (1985) A matter of principle. Cambridge, Massachusetts, London: Harvard University Press, 425 pp.

- Dworkin, Ronald (1989) Los derechos en serio. Traducción de Marta Gustavino. 2a ed., Barcelona: Editorial Ariel, 508 pp.

- Dworkin, Ronald (1999) Freedom's Law. Cambridge, Massachusetts: Harvard University Press, 404 pp. 
- Dworkin, Ronald (2005) El imperio de la justicia. Traducción de Claudia Ferrari. Barcelona: Editorial Gedisa S.A., 328 pp.

- Feijoo, Bernardo (1997) El injusto penal y su prevención ante el nuevo código penal de 1995. Madrid: Editorial Colex, 143 pp.

- Fernández, José Ángel (2010) "El juicio constitucional de proporcionalidad de la leyes penales: ¿La legitimación democrática como medio para mitigar su inherente irracionalidad?”. Revista de Derecho Universidad Católica del Norte, año 17, n 1, pp. 51 a 99.

- Fernández, Miguel Ángel (2009) "Conflictos entre Derechos Fundamentales en la jurisprudencia del Tribunal Constitucional". En: Pfeffer, Emilio (Coord.) Temas actuales de Derecho Constitucional. Libro homenaje a Mario Verdugo Marinkovic, Santiago: Editorial Jurídica de Chile, pp. 75 a 86.

- Guastini, Riccardo (2003) "La constitucionalización del ordenamiento jurídico: el caso italiano". Traducción de José María Lujambio. En: Carbonell Sánchez, Miguel (coord.) Neoconstitucionalismo (s). México: Trotta, pp. 49 a 74.

- Hart, Herbert (1998) El concepto de derecho. Traducción de Genaro Carrio. 2a ed., Buenos Aires: Abeledo Perrot, 332 pp.

- HayeK, Friedrich (1980) "El ideal democrático y la contención del poder". Estudios públicos, n 1 , pp. 12 a 75.

- Hierro, José (1986) Principios de filosofía del lenguaje. Madrid: Alianza Editorial, 504 pp.

- Hohfeld, W. H. (1992) Conceptos juridicos fundamentales. 2a ed., Trad.: Carrió, Genaro, Fontamara S. A., México, 90 pp.

- Hruschka, Joachim (1994) "Reglas de comportamiento y reglas de imputación”. Anuario de Derecho Penal, Fascículo III, septiembrediciembre, pp. 343 a 356.

- Hruschka, Joachim (2005) "Sobre la utilidad del hexágono deontológico para el derecho". Traducción de Pablo Sánchez-Ostiz. En: HruschKa, Joachim, Imputación y derecho penal. Estudios sobre la teoría de la imputación. Navarra: Aranzadi S.A., pp. 41 a 54.

- Jaковs, Günther (2000) Sociedad, norma y persona en una teoría de un derecho penal funcional. Traducción de Manuel Cancio y Bernardo Feijoo. Madrid: Editorial Civitas, 85 pp.

- Jаковs, Günther (2003) Sobre la normativización de la dogmática juridico-penal. Traducción de Manuel Cancio y Bernardo Feijoo. Madrid: Editorial Civitas, 163 pp.

- Jаковs, Günther (2004) ¿Qué protege el derecho penal: bienes juridicos o la vigencia de la norma? Mendoza: Ediciones Jurídicas Cuyo, 67 pp.

- Jаковs, Günther (2006) Terroristas como personas en derecho. Traducción de Manuel Cancio. Disponible en: http:// neopanopticum.wordpress.com/2008/08/30/\%c2\%bfterroristas- 
como-personas-en-derecho-g-jakobs/ [fecha de consulta: 14 de enero de 2013].

- Kelsen, Hans (1929) "La garantía jurisdiccional de la Constitución (La justicia constitucional)". Annuaire de l' Institut de Droit Public, pp. 9 a 107. Disponible en: http://biblio.juridicas.unam.mx/ libros/1/31/tc.pdf, 107 pp [fecha de consulta: 14 de enero de 2013].

- Kelsen, Hans (1995) ¿Quién debe ser el defensor de la Constitución? Traducción de Roberto Brie. 2a ed., Madrid: Tecnos, 82 pp.

- Kelsen, Hans (2008) Teoría pura del derecho. Traducción de Moisés Nilve. $4^{a}$ ed., Buenos Aires: Eudeba, 183 pp.

- KindhäUser, Urs (2005) “¿Indiferencia cómo dolo?”. Traducción de Percy García. En: Kindhäuser, Urs; García, Percy; Pastor, Nuria, Cuestiones actuales de derecho penal general y patrimonial. Lima: Universidad de Piura, pp. 33 a 54.

- KindhäUser, Urs (2009) "La lógica de la construcción del delito". Traducción de Juan Pablo Mañalich. Revista de Análisis Especializado de jurisprudencia, $\mathrm{n}^{\circ} 14,2009,11 \mathrm{pp}$.

- KindhäUser, Urs (2010) “¿Qué es la imprudencia?”. En: IV Seminario Internacional de Derecho Penal (16.09.2010), 13 pp. Disponible en: http://www.scribd.com/doc/38024280/Artculo-Profkindhuser-Que-Es-La-Imprudencia [fecha de consulta: 14 de enero de 2013].

- Lascuraín, Juan Antonio (2012) “¿Restrictivo o deferente? El control de la ley penal por parte del Tribunal Constitucional”. InDret, 3/2012, 33 pp.

- Lopera, Gloria (2011) "Principio de proporcionalidad y control constitucional de las leyes penales. Una comparación entre las experiencias de Chile y Colombia”. Revista de Derecho, Vol. XXIV, n ${ }^{\circ}$ 2, pp. 113 a 138.

- Mac-Clure, Lucas (2011) "Tribunal Constitucional y los derechos: la discusión pendiente". En: Sierra, Lucas; Mac-Clure, Lucas, Frente a la mayoria: leyes supramayoritarias y Tribunal Constitucional en Chile. Santiago: CEP, CIEPLAN y Libertad y Desarrollo, Proyectamérica, p. 170 a 275.

- Maccormick, Neil (2005) Rhetoric and the rule of law. A theory of legal reasoning. Oxford University Press: Oxford, 283 pp.

- Maccormick, Neil (2007) "La argumentación silogística: una defensa matizada". Doxa. Cuadernos de filosofía del derecho, $\mathrm{n}^{\circ} 30$, pp. 321 a 334.

- Mañalich, Juan Pablo (2005a) "Condiciones generales de la punibilidad". Revista de Derecho de la Universidad Adolfo Ibáñez, $\mathrm{n}^{\circ}$ 2, pp. 387 a 481. 
- Mañalich, Juan Pablo (2005b) "El concurso de delitos: base para su reconstrucción en el derecho penal de Puerto Rico". Revista Jurídica UPR, Vol. 74, pp. 1021 a 1211.

- Mañalich, Juan Pablo (2007) "La pena como retribución”. Estudios Públicos, $\mathrm{n}^{\circ} 108$, pp. 117 a 205.

- Mañalich, Juan Pablo (2010) "Norma e imputación como categoría del hecho punible". REJ, n 12, p. 169 a 190.

- Mañalich, Juan Pablo (2012) "Reglas primarias de obligación. Las reglas del derecho penal en el concepto de derecho de H. L. A. Hart”. Zeitschrift für Internationale Strafrechtsdogmatik, ${ }^{\circ} 11$, pp. 571 a 585.

- Martínez, José Ignacio; Zúñiga, Francisco (2011) "El principio de razonabilidad en la jurisprudencia del Tribunal Constitucional”. Estudios Constitucionales, ${ }^{\circ}$ 1, año 9, pp. 199 a 226.

- Mir, Santiago (2003) Introducción a las bases del derecho penal. 2a ed., Montevideo-Buenos Aires: B de f, 325 pp.

- Mir, Santiago (2011) Derecho Penal. Parte General. 9a ed., Barcelona: Reppetor, 814 pp.

- Moresco, Juan José (2008) "El positivismo jurídico, la interpretación del derecho y la aplicación de la Constitución”. Derecho y Humanidades, ${ }^{\circ} 14$, pp. 37 a 50.

- Navarro, Pablo (2011) "Permisos, enunciados normativos y proposiciones normativas”. XVII Seminario Hispano-Italiano-Francés de Teoria del Derecho (Getafe, 21-22 de octubre de 2011) (Getafe, Grupo de Investigación sobre el Derecho y la Justicia), 18 pp. Disponible en: http://e-archivo.uc3m.es/bitstream/10016/13857/1/ permisos_navarro_SHIF_2011.pdf [fecha de consulta: 14 de enero de 2013].

- Nino, Carlos Santiago (1989) Ética y derechos humanos. 2a ed., Buenos Aires: Astrea de Alfredo y Ricardo Depalma, 494 pp

- Nogueira, Humberto (2005) "El control represivo concreto y abstracto de inconstitucionalidad de las leyes en la reforma de las competencias del Tribunal Constitucional y los efectos de sus sentencias". Estudios Constitucionales, n 1, año 3, pp. 11 a 35

- Nogueira, Humberto (2006) "El derecho a la igualdad ante la ley, la no discriminación y acciones positivas". AFDUDC, n 10 , pp. 799 a 831.

- Nogueira, Humberto (2009a) "Las mutaciones de la Constitución producidas por vía interpretativa del Tribunal Constitucional. El Tribunal Constitucional ¿Poder constituido, o poder constituyente en sesión permanente? Estudios Constitucionales, n ${ }^{\circ} 2$, ańo 7, pp. 389 a 427. 
- Nogueira, Humberto (2009b) "Enfoques sobre interpretación constitucional y Jurisdicción constitucional". En: Pfeffer, Emilio (Coord.) Temas actuales de Derecho Constitucional. Libro homenaje a Mario Verdugo Marinkovic, Santiago: Editorial Jurídica de Chile, pp. 155 a 186.

- Nogueira, Humberto (2012) "La concepción de Constitución, el bloque de constitucionalidad de derecho fundamentales y el control de convencionalidad en la práctica jurisprudencial del tribunal Constitucional y la Corte suprema de Justicia de Chile". En: Pfeffer, Emilio (Coord.) Derechos Fundamentales. Libro homenaje a Francisco Cumplido Cereceda, Santiago: Editorial Jurídica de Chile, pp. 219 a 260.

- Prieto, Luis (2001) "Neoconstitucionalismo y ponderación judicial". AFDUAM, n 5, pp. 201 a 227.

- Putnam, Hilary (2002) The collapse of the fact/value dichotomy and other essays. Cambridge, Massachusetts, London: Harvard University Press, 190 pp.

- Rawls, John (1995) Teoría de la Justicia. Traducción de María González. 2a ed., México: Fondo de Cultura Económica, 549 pp.

- RAz, Joseph (1985a) La autoridad del derecho. Ensayos sobre derecho y moral. Traducción de Rolando Tamayo y Salmorán. 2a ed., México: Universidad Nacional Autónoma de México, 354 pp.

- Raz, Joseph (1985b) "Authority, law and Morality". The Monist, Vol. 68, Issue n 3, pp. 295 a 324.

- Raz, Joseph (1986) El concepto de sistema jurídico. Traducción de Rolando Tamayo y Salmorán. México: Universidad Autónoma de México, 289 pp.

- Raz, Joseph (1991) Razón práctica y normas. Traducción de Juan Ruiz. $2^{a}$ ed., Madrid: Centro de Estudios Constitucionales, 260 pp.

- Riddall, J.G. (1999) Teoría del Derecho. Traducción de TsEdi, Teleservicios Editoriales, S.L., Barcelona: Editorial Gedisa, 283 pp.

- Rodríguez, Jorge (2003) "Naturaleza y lógica de las proposiciones normativas. Contribución en homenaje a A. G. H. von Wright". Doxa, n ${ }^{\circ} 26$, pp. 87 a 108.

- Ruiz-Tagle, Pablo (2003) "La tesis de la doble pluralidad: jueces y democracia, el caso de la transición chilena 1990-2002". En: Malem, Jorge; Orozco, Jesús; VÁzQuez, Rodolfo (comp.) La función judicial. Etica y democracia. Barcelona: Gedisa, pp. 275 a 293.

- Ruiz-Tagle, Pablo (2005) "La vulgarización como eslogan y los derechos fundamentales". REJ, $\mathrm{n}^{\circ} 11$, pp. 151 a 159.

- Sant'ana, Adriano (2012) "Mutación constitucional y concreción normativa: cómo la estructura de la norma se relaciona con los 
cambios informales de la Constitución”. Estudios Constitucionales, ańo $10, \mathrm{n}^{\circ} 2$, pp. 369 a 390.

- Schmitt, Carl (1996) Teoría de la Constitución. Traducción de Francisco Ayala. Madrid: Alianza Universidad Textos, 377 pp.

- Schmitt, Carl (1998) El concepto de lo politico. Traducción de Rafael Agapito. Madrid: Alianza Editorial, 153 pp.

- Searle, John (1968) "Austin on locutionary and illocutionary acts". The Philosophical Review, Vol. 77, n 4, pp. 405 a 424.

- Searle, John (1976) "A classification of illocutionary acts". Language in society, Vol. 5, $\mathrm{n}^{\circ} 1$, pp. 1 a 23.

- Searle, John (1997) La construcción de la realidad social. Traducción de Antoni Domenech. Barcelona-Buenos Aires: Paidós, 236 pp.

- Searle, John (2007) Actos del habla. Ensayo de filosofía del lenguaje. Traducción de Luis Valdés Villanueva. 6 ${ }^{a}$ ed., Madrid: Ediciones Cátedra, 201 pp.

- SeArle, John (2010) Making the social world. The structure of human civilization. New York: Oxford University Press, 208 pp.

- SEN, Amartya (1967) "The Nature and Classes of Prescriptive Judgments". The Philosophical Quarterly, Vol. 17, No. 66, pp. 46 a 62.

- Shklar, Judith (1968) Legalismo. Traducción de Isabel Giménez. Buenos Aires: Bibliográfica Omeba, 237 pp.

- Sierra, Lucas (2012) "Quórum legislativo de supramayoría y Tribunal Constitucional en Chile”. SELA 2012. Pappers and Programs, 21 pp. Disponible en: http://www.law.yale.edu/ documents/pdf/sela/SELA12_Sierra_CV_Sp_20120409.pdf [fecha de consulta: 14 de enero de 2013].

- Silva, Jesús (2003) Normas y acciones en el derecho penal. Buenos Aires: Hammurabi, 145 pp.

- Silva, Jesús (2008) "La interpretación de la leyes y la cultura de los juristas”. En: Montealegre, Eduardo; Caro John, José (edit.) El sistema penal normativista en el mundo contemporáneo: Libro homenaje al Profesor Günther Jakobs en su 70 aniversario. Bogotá: Universidad Externado de Colombia, 2008, pp. 201 a 213.

- Silva, Jesús (2010) Aproximación al derecho penal contemporáneo. 2a ed., Montevideo-Buenos Aires: B de f, 689 pp.

- Strles, William (1993) "Clasificación de actos ilocutivos intersubjetivos". Anuario de Psicología, n 59, pp. 79 a 103.

- Szczaranski, Federico (2012) "Sobre la evolución del bien jurídico penal: un intento de saltar más allá de la propia sombra”. Política Criminal, Vol. 7, n 14 , pp. 378 a 453. 
- Tremblay, Luc (2003) "General legitimacy of judicial review and the fundamental basis of constitutional law". Oxford Journal of Legal Studies, Vol. 23, n 4, pp. 252 a 562.

- Tur, Richard (2001) "Defeasibilism". Oxford Journal of legal Studies, Vol. 21, n 2, pp. 355 a 368.

- Valenzuela, Eugenio (2006) Criterios de hermenéutica constitucional aplicados por el tribunal constitucional: Contribución del Tribunal Constitucional a la institucionalización democrática. Santiago: LOM, $125 \mathrm{pp}$.

- Villacorta, Luis (2011) "Jurisdicción constitucional y derechos fundamentales. Aspectos a destacar en la discusión española”. Ius et Praxis, $\mathrm{n}^{\circ} 1$, año 17 , pp. 81 a 118.

- Von Savigny, Friedrich (1878) Sistema del derecho romano actual, Tomo 1. Traducción de Jacinto Mesía y Manuel Poley. Madrid: F. Góngora y compañía.

- Von Wright, Georg Henrik (1970) Norma y acción. Una investigación lógica. Traducción de Pedro García. Madrid: Tecnos, $216 \mathrm{pp}$.

- VV.AA. (2011) "La inconstitucionalidad del artículo 365 del Código Penal. Informe en derecho". REJ, $\mathrm{n}^{\circ} 14$, pp. 73 a 109.

- Waldron, Jeremy (1999a) Law and Disagreement. New York: Oxford University Press, $332 \mathrm{pp}$.

- Waldron, Jeremy (1999b) The Dignity of Legislation. Cambridge: Cambridge University Press, 206 pp.

- Wroblewski, Jerzy (1985) Constitución y teoría de la interpretación jurídica. Traducción de Arantxa Azurza, Madrid: Civitas, 114 pp.

- Zapata, Patricio (2008) Justicia constitucional: Teoría y práctica en el derecho chileno y comparado. Santiago: Editorial Jurídica de Chile, $623 \mathrm{pp}$.

- ZúŃIgA, Yanira (2010) "El principio de proporcionalidad como herramienta de proporcionalidad. Un análisis crítico de su aplicación en la jurisprudencia del Tribunal Constitucional chileno". Ius et Praxis, $\mathrm{n}^{\circ} 2$, año 16, pp. 249 a 272. 